\title{
Congenital Hypothyroidism: A 2020-2021 Consensus Guidelines Update- An ENDO-European Reference Network Initiative Endorsed by the European Society for Pediatric Endocrinology and the European Society for Endocrinology
}

\author{
Paul van Trotsenburg, ${ }^{1, *}$ Athanasia Stoupa, ${ }^{2-5, *}$ Juliane Léger, ${ }^{6,7}$ Tilman Rohrer, ${ }^{8}$ Catherine Peters, ${ }^{9}$ \\ Laura Fugazzola, ${ }^{10,11}$ Alessandra Cassio, ${ }^{12}$ Claudine Heinrichs, ${ }^{13}$ Veronique Beauloye, ${ }^{14}$ Joachim Pohlenz, ${ }^{15}$ \\ Patrice Rodien, ${ }^{16}$ Regis Coutant, ${ }^{17}$ Gabor Szinnai, ${ }^{18}$ Philip Murray, ${ }_{19,20}$ Beate Bartés, ${ }^{21}$ Dominique Luton, ${ }^{22,23}$ \\ Mariacarolina Salerno, ${ }^{24}$ Luisa de Sanctis, ${ }^{25}$ Mariacristina Vigone, ${ }^{26}$ Heiko Krude, ${ }^{27}$ \\ Luca Persani, ${ }^{28,29}$ and Michel Polak ${ }^{2-5,30-32}$
}

\footnotetext{
${ }^{1}$ Department of Pediatric Endocrinology, Emma Children's Hospital, Amsterdam University Medical Centers, University of Amsterdam, Amsterdam, Netherlands.

${ }^{2}$ Pediatric Endocrinology, Gynecology and Diabetology Department, Assistance Publique Hôpitaux de Paris (APHP), Hôpital Universitaire Necker Enfants Malades, Paris, France.

${ }^{3}$ Université de Paris, Paris, France.

${ }^{4}$ INSERM U1163, IMAGINE Institute, Paris, France.

${ }^{5}$ INSERM U1016, Cochin Institute, Paris, France.

${ }^{6}$ Department of Pediatric Endocrinology and Diabetology, Reference Center for Growth and Development Endocrine Diseases, Assistance Publique-Hôpitaux de Paris, Robert Debré University Hospital, Paris, France.

${ }^{7}$ Institut National de la Santé et de la Recherche Médicale (INSERM), UMR 1141, Paris, France.

${ }^{8}$ Department of Pediatric Endocrinology, University Children's Hospital, Saarland University Medical Center, Homburg, Germany.

${ }^{9}$ Department of Pediatric Endocrinology, Great Ormond Street Hospital for Children, London, United Kingdom.

${ }^{10}$ Department of Endocrinology and Metabolic Diseases, IRCCS Istituto Auxologico Italiano, Milan, Italy.

${ }^{11}$ Department of Pathophysiology and Transplantation, University of Milan, Milan, Italy.

${ }^{12}$ Department of Pediatric Endocrinology, Unit of Pediatrics, Department of Medical \& Surgical Sciences, University of Bologna, Bologna Italy.

${ }^{13}$ Pediatric Endocrinology Unit, Hôpital Universitaire des Enfants Reine Fabiola, Université Libre de Bruxelles, Brussels, Belgium.

${ }^{14}$ Unité d'Endocrinologie Pédiatrique, Cliniques Universitaires Saint-Luc, Université Catholique de Louvain, Brussels, Belgium.

${ }^{15}$ Department of Pediatrics, Johannes Gutenberg University Medical School, Mainz, Germany.

${ }^{16}$ Centre de Référence des Maladies Rares de la Thyroïde et des Récepteurs Hormonaux, Service EDN, CHU d'Angers, Institut MITOVASC, Université d'Angers, Angers, France.

${ }^{17}$ Unité d' Endocrinologie Diabetologie Pédiatrique and Centre des Maladies Rares de la Réceptivité Hormonale, CHU-Angers, Angers, France.

${ }^{18}$ Department of Pediatric Endocrinology, University Children's Hospital Basel, University of Basel, Basel, Switzerland.

${ }^{19}$ European Society for Pediatric Endocrinology.

${ }^{20}$ Department of Paediatric Endocrinology, Royal Manchester Children's Hospital, Manchester University NHS Foundation Trust, Manchester, United Kingdom.

${ }^{21}$ Thyroid Group, European Patient Advocacy Group Patient Representative (ePAG), Association Vivre sans Thyroide, Léguevin, France.

${ }^{22}$ Department of Obstetrics and Gynecology, University Hospitals Paris Nord Val de Seine (HUPNVS), Assistance Publique Hôpitaux de Paris (APHP), Bichat Hospital, Paris, France.

${ }^{23}$ Department Risks and Pregnancy (DHU), Université de Paris, Inserm U1141, Paris, France.

${ }^{24}$ Pediatric Endocrine Unit, Department of Translational Medical Sciences, University of Naples Federico II, Naples, Italy.

${ }^{25}$ Department of Public Health and Pediatrics, University of Turin, Regina Margherita Children's Hospital, Turin, Italy.

${ }^{26}$ Department of Pediatrics, IRCCS San Raffaele Hospital, Vita-Salute San Raffaele University, Milan, Italy.

${ }^{27}$ Institut für Experimentelle Pädiatrische Endokrinologie, Charité - Universitätsmedizin Berlin, Berlin, Germany.

${ }^{28}$ Department of Clinical Sciences and Community Health, University of Milan, Milan, Italy.

${ }^{29}$ Department of Endocrine and Metabolic Diseases, IRCCS Istituto Auxologico Italiano, Milan, Italy.

${ }^{30}$ Paris Regional Newborn Screening Program, Centre régional de dépistage néonatal, Paris, France.

${ }^{31}$ Centre de Référence Maladies Endocriniennes de la Croissance et du Développement, INSERM U1016, IMAGINE Institute, Paris, France.

${ }^{32}$ ENDO-European Reference Network, Main Thematic Group 8, Paris, France.

*These authors contributed equally to this work.
}

(C) Paul van Trotsenburg et al., 2021; Published by Mary Ann Liebert, Inc. This Open Access article is distributed under the terms of the Creative Commons Attribution Noncommercial License [CC-BY-NC] (http://creativecommons.org/licenses/by-nc/4.0/) which permits any noncommercial use, distribution, and reproduction in any medium, provided the original author(s) and the source are cited. 
Background: An ENDO-European Reference Network (ERN) initiative was launched that was endorsed by the European Society for Pediatric Endocrinology and the European Society for Endocrinology with 22 participants from the ENDO-ERN and the two societies. The aim was to update the practice guidelines for the diagnosis and management of congenital hypothyroidism $(\mathrm{CH})$. A systematic literature search was conducted to identify key articles on neonatal screening, diagnosis, and management of primary and central $\mathrm{CH}$. The evidence-based guidelines were graded with the Grading of Recommendations, Assessment, Development and Evaluation system, describing both the strength of recommendations and the quality of evidence. In the absence of sufficient evidence, conclusions were based on expert opinion.

Summary: The recommendations include the various neonatal screening approaches for $\mathrm{CH}$ as well as the etiology (also genetics), diagnostics, treatment, and prognosis of both primary and central $\mathrm{CH}$. When $\mathrm{CH}$ is diagnosed, the expert panel recommends the immediate start of correctly dosed levothyroxine treatment and frequent follow-up including laboratory testing to keep thyroid hormone levels in their target ranges, timely assessment of the need to continue treatment, attention for neurodevelopment and neurosensory functions, and, if necessary, consulting other health professionals, and education of the child and family about $\mathrm{CH}$. Harmonization of diagnostics, treatment, and follow-up will optimize patient outcomes. Lastly, all individuals with $\mathrm{CH}$ are entitled to a well-planned transition of care from pediatrics to adult medicine.

Conclusions: This consensus guidelines update should be used to further optimize detection, diagnosis, treatment, and follow-up of children with all forms of $\mathrm{CH}$ in the light of the most recent evidence. It should be helpful in convincing health authorities of the benefits of neonatal screening for $\mathrm{CH}$. Further epidemiological and experimental studies are needed to understand the increased incidence of this condition.

Keywords: congenital hypothyroidism, guidelines, thyroid dysgenesis, dyshormonogenesis, central hypothyroidism, neonatal screening

\section{INTRODUCTION}

C ONGENITAL HYPOTHYROIDISM $(\mathrm{CH})$ can be defined as (variable) dysfunction of the hypothalamic-pituitarythyroid (HPT) axis present at birth, resulting in insufficient thyroid hormone $(\mathrm{TH})$ production and, with that, severeto-mild $\mathrm{TH}$ deficiency. $\mathrm{CH}$ may be caused by abnormal development or function of the thyroid gland, or of the hypothalamus and pituitary, but also to impaired TH action.

In 2014, an international consensus guideline on $\mathrm{CH}$ was published that encompassed the scientific literature up to 2013 (1). An ENDO-European Reference Network (ERN) initiative was launched, which was endorsed by the European Society for Pediatric Endocrinology and the European Society for Endocrinology, with the aim to update the practice guidelines for the diagnosis and management of $\mathrm{CH}$.

\section{METHODS}

Twenty-two participants from the ENDO-ERN network, Main Thematic Group 8-thyroid, including an ENDO-ERN patient association representative, and from the two scientific societies, the European Society for Pediatric Endocrinology and the European Society for Endocrinology participated. Preparation for the consensus took $\sim 24$ months, starting late 2017 including email exchanges and two preparatory faceto-face meetings organized in 2019. All coauthors performed a comprehensive literature research using PudMed including articles published from January 1, 2013 to present (late 2020) concerning the five different subthemes presented in the consensus. Publications before 2013 have already been considered in the previous $\mathrm{CH}$ consensus published in 2014. Only publications in English were considered.

A comprehensive review of all selected articles formed the basis of discussion and writing for the five working groups (WGs): WG1: neonatal screening, WG2: diagnosis and criteria for treatment, WG3: treatment and monitoring, WG4: outcomes of neonatal screening and early treatment, and WG5: genetics of $\mathrm{CH}$ and antenatal management. A preliminary document summarizing the questions addressed in the preparatory meetings was prepared by each WG and shared for review with all the experts before the final meeting. At the final consensus meeting, propositions and recommendations were reconsidered by participants and discussed in plenary sessions, enabling any reformulation of the recommendations. Recommendations were based on best available research evidence. Best practice statements were considered when necessary and, if evidence is mixed, based on expert opinion.

A detailed description of the grading scheme Grading of Recommendations Assessment, Development and Evaluation (GRADE) has been published elsewhere (2). Factors that influence the strength of the recommendation (strong vs. weak) include the quality of evidence, the balance between benefits and risks, the burden of interventions, and the cost.

For each point, recommendations and evidence are described, with a modification in the grading evidence, as follows: $1=$ strong recommendation (applies to most patients in most circumstances, benefits clearly outweigh the risk); 2 = weak recommendation (suggested by us or should be considered; the best action may depend on circumstances or patient values, benefits, and risks closely balanced or uncertain). Quality of evidence is indicated as follows: +00: low (case series or nonsystematic clinical observations, inconsistent and unprecise estimates, or with indirect evidence); ++0: moderate (studies with methodological flaws, inconsistent or indirect evidence); +++: high quality (low risk bias). 


\section{Summary of the $\mathrm{CH}$ consensus guidelines update}

1. Neonatal screening

\subsection{The benefits of $\mathrm{CH}$ screening}

- Early detection and treatment of $\mathrm{CH}$ through neonatal screening prevent irreversible neurodevelopmental delay and optimize its developmental outcome $(1 /+++)$.

- Screening for $\mathrm{CH}$ should be introduced worldwide $(1 /+++)$.

\subsection{Analytical methodology and effectiveness of $\mathrm{CH}$} screening strategies

- The incidence of $\mathrm{CH}$ partly depends on the screening strategy; based on data from a number of screening programs, the incidence of primary $\mathrm{CH}$ lies between 1 in 3000 and 1 in 2000; the highest reported incidence of central $\mathrm{CH}$ is $\sim 1$ in $16,000(1 /+++)$.

- The initial priority of neonatal screening for $\mathrm{CH}$ should be the detection of all forms of primary $\mathrm{CH}-$ mild, moderate, and severe; the most sensitive test for detecting primary $\mathrm{CH}$ is measurement of thyrotropin (TSH) $(1 /+++)$.

- When financial resources are available, we recommend adding measurement of total or free thyroxine (fT4) to $\mathrm{TSH}$, to screen for central $\mathrm{CH}(2 /++0)$.

1.3. Postscreening strategies in special categories of neonates at risk of $\mathrm{CH}$

- Some groups of children may have a false-negative neonatal screening result or have a high risk of mild $\mathrm{CH}$ not detected by neonatal screening, for instance premature, low birthweight, and sick babies; for these groups a postscreening strategy including collection of a second specimen $\sim 10$ to 14 days of age may be considered $(1 /+00)$.

- In patients with Down's syndrome, we recommend measuring TSH at the end of the neonatal period $(1 /++0)$.

- The initial screening in an affected twin may be normal; a second screening in same sex twins should be considered. The nonaffected sibling of twins should be followed up for possible TSH elevation later in life (2/+00).

- Clinical suspicion of hypothyroidism, despite normal TSH in TSH-based screening programs, should prompt further evaluation for primary (rare cases of falsenegative neonatal screening results) and central $\mathrm{CH}$, particularly in children with a family history of central $\mathrm{CH}(2 /+00)$.

\section{Diagnostics and criteria for treatment}

2.1. Biochemical criteria used in the decision to start treatment for $\mathrm{CH}$

- A newborn with an abnormal neonatal screening result should be referred to an expert center $(1 /++0)$.

- An abnormal screening result should be followed by confirmatory testing consisting of measurement of serum fT4 and TSH $(1 /++0)$.

- If the serum fT4 concentration is below and TSH clearly above the age-specific reference interval, then levothyroxine (LT4) treatment should be started immediately $(1 /+++)$.
- If the serum TSH concentration is $>20 \mathrm{mU} / \mathrm{L}$ at confirmatory testing (approximately in the second week of life), treatment should be started, even if fT4 is normal (arbitrary threshold, expert opinion) $(2 /+00)$.

- If the serum TSH concentration is 6-20 mU/L beyond the age of 21 days in a healthy neonate with an fT4 concentration within the age-specific reference interval, we suggest to either start LT4 treatment immediately and retest, off-treatment, at a later stage, or to withhold treatment but retest 1 to 2 weeks later and to re-evaluate the need for treatment (lack of evidence in favor or against treatment, this is an area of further investigation) $(2 /++0)$.

- In countries or regions where thyroid function tests are not readily available, LT4 treatment should be started if filter paper TSH concentration is $>40 \mathrm{mU} / \mathrm{L}$ (at the moment of neonatal screening; arbitrary threshold, expert opinion) $(2 /+00)$.

- If the serum fT4 is low, and TSH is low, normal or slightly elevated, the diagnosis central $\mathrm{CH}$ should be considered $(1 /++0)$.

- In neonates with central $\mathrm{CH}$, we recommend to start LT4 treatment only after evidence of intact adrenal function; if coexistent central adrenal insufficiency cannot be ruled out, LT4 treatment must be preceded by glucocorticoid treatment to prevent possible induction of an adrenal crisis $(2 /+00)$.

\subsection{Communication of abnormal screening and confir-} matory results

- An abnormal neonatal screening result should be communicated by an experienced professional (e.g., member of pediatric endocrine team, pediatrician, or general physician) either by telephone or face to face, and supplemented with written information for the family (2/+00).

\subsection{Imaging techniques in $\mathrm{CH}$}

- In patients with a recent $\mathrm{CH}$ diagnosis, we strongly recommend starting LT4 treatment before conducting thyroid gland imaging studies $(1 /++0)$.

- We recommend imaging of the thyroid gland using either radioisotope scanning (scintigraphy) with or without the perchlorate discharge test, or ultrasonography (US), or both $(1 /++0)$.

- Knee X-ray may be performed to assess the severity of intrauterine hypothyroidism $(2 /+00)$.

\subsection{Associated malformations and syndromes}

- All neonates with a high TSH concentration should be examined carefully for dysmorphic features suggestive for syndromic $\mathrm{CH}$, and for congenital malformations (particularly cardiac) $(1 /+++)$.

\section{Treatment and monitoring of $\mathrm{CH}$}

\subsection{Starting treatment for primary $\mathrm{CH}$}

- LT4 alone is recommended as the medication of choice for the treatment of $\mathrm{CH}(1 /++0)$.

- LT4 treatment should be started as soon as possible, not later than 2 weeks after birth or immediately after 
confirmatory (serum) thyroid function testing in neonates in whom $\mathrm{CH}$ is detected by a second routine screening test $(1 /++0)$.

- The LT4 starting dose should be up to $15 \mu \mathrm{g} / \mathrm{kg}$ per day, taking into account the whole spectrum of $\mathrm{CH}$, ranging from mild to severe $(1 /++0)$.

- Infants with severe $\mathrm{CH}$, defined by a very low pretreatment serum fT4 $(<5 \mathrm{pmol} / \mathrm{L})$ or total T4 concentration in combination with elevated TSH (above the normal range based on time since birth and gestational age (GA), should be treated with the highest starting dose $(10-15 \mu \mathrm{g} / \mathrm{kg}$ per day) $(1 /++0)$.

- Infants with mild CH (fT4>10 pmol/L in combination with elevated TSH) should be treated with the lowest initial dose $(\sim 10 \mu \mathrm{g} / \mathrm{kg}$ per day); in infants with pretreatment fT4 concentrations within the age-specific reference interval an even lower starting dose may be considered (from 5 to $10 \mu \mathrm{g} / \mathrm{kg})(1 /++0)$.

- LT4 should be administered orally, once a day $(1 /++0)$.

- The evidence favoring brand versus generic LT4 is mixed but based on personal experience/expert opinion we recommend brand rather than generic $(2 /++0)$.

\subsection{Monitoring treatment in primary $\mathrm{CH}$}

- We recommend measurement of serum fT4 and TSH concentrations before or at least 4 hours after the last (daily) LT4 administration $(1 /++0)$.

- We recommend evaluation of fT4 and TSH according to age-specific reference intervals $(1 /++0)$.

- The first treatment goal in neonates with primary $\mathrm{CH}$ is to rapidly increase the circulating amount of $\mathrm{TH}$, reflected by normalization of serum TSH; therafter, TSH should be kept within the reference interval.

- If TSH is in the age-specific reference interval, fT4 concentrations above the upper limit of the reference interval can be accepted and recommend maintaining the same LT4 dose $(1 /++0)$.

- Any reduction of the LT4 dose should not be based on a single higher than normal fT4 concentration, unless TSH is suppressed (i.e., below the lower limit of the reference interval) or there are signs of overtreatment (e.g., jitteriness or tachycardia) $(1 /++0)$.

- The first clinical and biochemical follow-up evaluation should take place 1 to 2 weeks after the start of LT4 treatment ( 1 week at the latest in case of a starting dose of $50 \mu \mathrm{g}$ per day or an even higher dose) $(1 /+00)$.

- Subsequent (clinical and biochemical) evaluation should take place every 2 weeks until complete normalization of serum TSH is achieved; therafter, the evaluation frequency can be lowered to once every 1 to 3 months until the age of 12 months $(1 /+00)$.

- Between the ages of 12 months and 3 years, the evaluation frequency can be lowered to every 2 to 4 months; thereafter, evaluations should be carried out every 3 to 6 months until growth is completed $(1 /+00)$.

- If abnormal fT4 or TSH values are found, or if compliance is questioned, the evaluation frequency should be increased $(2 /+00)$.

- After a change of LT4 dose or formulation, an extra evaluation should be carried out after 4 to 6 weeks $(2 /+00)$
- We recommend physicians to avoid long-term underor overtreatment during childhood $(1 /++0)$.

- In contrast to adults, in neonates, infants, and children, LT4 can be administered together with food (but with avoidance of soy protein and vegetable fiber); more important, LT4 should be administered at the same time every day, also in relation to food intake; while this approach can improve compliance, it ensures as constant as possible LT4 absorption and, with that, as good as possible LT4 dose titration (2/+00).

- In case of an unexpected need for LT4 dose increase, reduced absorption, or increased metabolization of thyroxine (T4) by other disease (e.g., gastrointestinal), food or medication should be considered $(2 /+00)$; incompliance may be the most frequent cause, especially in teenagers and adolescents.

\subsection{Treatment and monitoring of central $\mathrm{CH}$}

- In severe forms of central CH (fT4 $<5$ pmol/L), we also recommend to start LT4 treatment as soon as possible after birth at doses like in primary $\mathrm{CH}(10-15 \mu \mathrm{g} / \mathrm{kg}$ per day, see section 3.1 ), to bring fT4 rapidly within the normal range $(1 /++0)$.

- In milder forms of central $\mathrm{CH}$, we suggest starting treatment at a lower LT4 dose $(5-10 \mu \mathrm{g} / \mathrm{kg}$ per day), to avoid the risk of overtreatment $(1 /++0)$.

- In newborns with central $\mathrm{CH}$, we recommend monitoring treatment by measuring fT4 and TSH according to the same schedule as for primary $\mathrm{CH}$; serum $\mathrm{fT} 4$ should be kept above the mean/median value of the age-specific reference interval; if TSH is low before treatment, subsequent TSH determinations can be omitted $(1 /+00)$.

- When under- or overtreatment is suspected in a patient with central $\mathrm{CH}$, then TSH, or free triiodothyronine (fT3) or total triiodothyronine (T3) can be measured $(1 /+00)$.

- When fT4 is around the lower limit of the reference interval, then undertreatment should be considered, particularly if TSH $>1.0 \mathrm{mU} / \mathrm{L}(1 /+00)$.

- When serum fT4 is around or above the upper limit of the reference interval, then overtreatment should be considered (assuming that LT4 has not been administered just before blood withdrawal), particularly if associated with clinical signs of thyrotoxicosis, or a high fT3 concentration $(1 /+00)$.

\subsection{Diagnostic re-evaluation of thyroid function beyond} the first 6 months of life

- When no definitive diagnosis of permanent $\mathrm{CH}$ was made in the first weeks or months of life, then reevaluation of the HPT axis after the age of 2 to 3 years is indicated, particularly in children with a gland in situ (GIS), and in those with presumed isolated central $\mathrm{CH}$ $(1 /++0)$.

- For a precise diagnosis, LT4 treatment should be phased out over a 4 to 6 weeks period or just stopped, and full re-evaluation should be carried out after 4 weeks, consisting of (at least) fT4 and TSH measurement.

- If primary hypothyroidism is confirmed (TSH $\geq 10 \mathrm{mU} / \mathrm{L}$ ), consider thyroid imaging and, if possible, genetic testing; 
if central $\mathrm{CH}$ is likely (fT4 below the lower limit of the reference interval in combination with a low normal of only mildly elevated TSH), consider evaluating the other anterior pituitary functions and genetic testing.

- If TSH is above the upper limit of the reference interval but $<10 \mathrm{mU} / \mathrm{L}$ (primary $\mathrm{CH}$ ) or fT4 just above the lower limit of the reference interval (central $\mathrm{CH}$ ), then continue withdrawal and retest in another 3 to 4 weeks $(1 /++0)$.

- If a child with no permanent $\mathrm{CH}$ diagnosis and a GIS requires a LT4 dose less than $3 \mu \mathrm{g} / \mathrm{kg}$ per day at the age of 6 months, then re-evaluation can be done already at that time $(1 /++0)$.

- We recommend avoiding iodine as an antiseptic during peri- and neonatal period, as it can cause transient $\mathrm{CH}$ $(1 /++0)$.

\section{$\mathrm{CH}$}

3.5. Treatment and monitoring of pregnant women with

- In women with $\mathrm{CH}$ who are planning pregnancy, we strongly recommend optimization of LT4 treatment; in addition, these women should be counseled regarding the higher need for LT4 during pregnancy $(1 /++0)$.

- fT4 (or total T4) and TSH levels should be monitored every 4 to 6 weeks during pregnancy, aiming at TSH concentrations in accordance with current guidelines on treatment of hypothyroidism during pregnancy, that is, $<2.5 \mathrm{mU} / \mathrm{L}$ throughout gestation in patients treated with LT4 (1/+00).

- In pregnant women with central $\mathrm{CH}$, the LT4 doses should be increased aiming at an fT4 concentration above the mean/median value of the trimester specific reference interval $(1 /+00)$.

- After delivery, we recommend lowering LT4 dose to preconception dose; additional thyroid function testing should be performed at $\sim 6$ weeks postpartum $(1 /++0)$.

- All pregnant women should ingest $\sim 250 \mu \mathrm{g}$ iodine per day $(1 /++0)$.

\section{Outcomes of neonatal screening and early treatment}

\subsection{Neurodevelopmental outcomes}

- Psychomotor development and school progression should be periodically evaluated in all children with $\mathrm{CH}$; speech delay, attention, and memory problems, and behavioral problems are reasons for additional evaluation $(1 /++0)$.

- In the small proportion of children with $\mathrm{CH}$ who do display significant psychomotor developmental delay and syndromic $\mathrm{CH}$ with brain abnormalities, it is crucial to rule out other causes of intellectual impairment than $\mathrm{CH}(1 /+00)$.

- Not just neonatal, but also repeated hearing tests should be carried out before school age and, if required, during further follow-up $(2 /++0)$.

\subsection{Development of goiter in thyroid dyshormonogenesis}

- Children and adolescents with primary $\mathrm{CH}$ due to dyshomonogenesis may develop goiter and nodules; in these cases, serum TSH should be carefully targeted in the lower part of normal range and periodical ultrasound investigation is recommended to monitor thyroid volume $(2 /++0)$.

- Since a few cases of thyroid cancer have been reported, fine needle aspiration biopsy for cytology should be performed in case of suspicious nodules on ultrasound investigation $(1 /+00)$.

\subsection{Growth, puberty, and fertility}

- Adequately treated children with nonsyndromic $\mathrm{CH}$ have normal growth and puberty, and their fertility does not differ from individuals who do not have $\mathrm{CH}$ $(1 /+++)$.

\subsection{Bone, metabolic, and cardiovascular health}

- Adequately treated children with nonsyndromic $\mathrm{CH}$ also have normal bone, metabolic, and cardiovascular health $(1 /++0)$.

4.5. Patient and professional education, and healthrelated quality of life

- Medical education about $\mathrm{CH}$ should be improved at all levels, with regular updates $(1 /+++)$.

- Education of parents, starting at the time of diagnosis, and later on of the patient is essential; not only throughout childhood, but also during transition to adult care and in women during pregnancy $(1 /+++)$.

- Since adherence to treatment may influence the outcomes, it should be promoted throughout life $(1 /++0)$.

\subsection{Transition to adult care}

- When patients are transferred from pediatric to adult care, the main aims are continuity of care and, with that, optimal clinical outcomes and quality of life, and to increase understanding of $\mathrm{CH}$ and promote selfmanagement $(1 /+++)$.

\section{Genetics of $\mathrm{CH}$, genetic counseling, and antenatal management}

\subsection{Criteria for genetic counseling}

- Genetic counseling should be targeted rather than general (to all $\mathrm{CH}$ patients) and done by an experienced professional $(2 /++0)$.

- Counseling should include explaining inheritance and the risk of recurrence of the patient's primary or central form of $\mathrm{CH}$, based on the $\mathrm{CH}$ subtype, the family history, and, if known, the (genetic) cause $(1 /++0)$.

- Parents with a child, or families with a member with $\mathrm{CH}$ should have access to information about the two major forms of primary $\mathrm{CH}$-thyroid dysgenesis (TD) and dyshormonogenesis - and, if included in the neonatal screening, about central $\mathrm{CH}(1 /+++)$.

\subsection{Genetics of $\mathrm{CH}$}

- If genetic testing is performed, its aim should be improving diagnosis, treatment, or prognosis $(1 /++0)$.

- Before doing so, possibilities and limits of genetic testing should be discussed with parents or families $(1 /++0)$. 
- When available, genetic testing should be performed by means of new techniques, such as comparative genomic hybridization $(\mathrm{CGH})$ array, next-generation sequencing (NGS) of gene panels (targeted NGS), or whole exome sequencing (WES) $(1 /++0)$.

- Preferably, genetic testing or studies should be preceded by careful phenotypic description of the patient's $\mathrm{CH}$, including morphology of the thyroid gland $(2 /++0)$.

- Not only thyroid dyshormonogenesis, but also familial occurrence of dysgenesis and central hypothyroidism should lead to further genetic testing $(1 /++0)$.

- Any syndromic association should be studied genetically, not only to improve genetic counseling, but also to identify new candidate genes explaining the association $(1 /++0)$.

- Further research is needed to better define patients or patient groups that will benefit most from these new diagnostic possibilities $(2 /++0)$.

\subsection{Antenatal diagnostics, evaluation of fetal thyroid function, and management of fetal hypothyroidism}

- We recommend antenatal diagnosis in cases of goiter fortuitously discovered during systematic ultrasound examination of the fetus, in relation to thyroid dyshormonogenesis $(1 /+++)$; a familial recurrence of $\mathrm{CH}$ due to dyshormonogenesis $(25 \%$ recurrence rate) $(1 /+++)$; and known defects of genes involved in thyroid function or development with potential germline transmission $(1 /++0)$.

Special issues should be considered for syndromic cases with potential mortality and possible germline mosaicism (as for NKX2-1 gene mutation/deletion and severe pulmonary dysfunction with possible transmission through germline mosaicism). In such circumstances, the discussion of the prenatal diagnosis should be open. The therapeutic management of affected fetuses should comply with the laws in force in the country concerned $(1 /++0)$. The familial recurrence of $\mathrm{CH}$ due to dysgenesis ( $2 \%$ of familial occurrences) requires further study to determine the feasibility and clinical relevance for antenatal detection.

- For the evaluation of fetal thyroid volume, we recommend ultrasound scans at 20 to 22 gestational weeks to detect fetal thyroid hypertrophy and potential thyroid dysfunction in the fetus. Goiter or an absence of thyroid tissue can also be documented by this technique. Measurements should be made as a function of GA, and thyroid perimeter and diameter should be measured to document goiter $(1 /+++)$.

- If a (large) fetal goiter is diagnosed, prenatal care should be provided in a specialized center of prenatal care $(1 /+++)$.

- We recommend cordocentesis, rather than amniocentesis, as the reference method for assessing fetal thyroid function. Norms have been established as a function of GA. This examination should be carried out only if prenatal intervention is considered $(1 /+++)$.

- In most cases, fetal thyroid function can be inferred from context and ultrasound criteria, and fetal blood sampling is, therefore, only exceptionally required $(2 /++0)$.

- We strongly recommend fetal treatment by intraamniotic T4 injections in a euthyroid pregnant woman with a large fetal goiter associated with hydramnios and/or tracheal occlusion; in a hypothyroid pregnant woman, we recommend to treat the woman (rather the fetus) with $\mathrm{T} 4(1 /++0)$.

- For goitrous nonimmune fetal hypothyroidism leading to hydramnios, we recommend intra-amniotic injections of LT4 to decrease the size of the fetal thyroid gland. The injections should be performed by multidisciplinary specialist teams $(1 /+++)$.

- The expert panel proposes the use of $10 \mu \mathrm{g} / \mathrm{kg}$ estimated fetal weight per 15 days in the form of intraamniotic injections. The risks to the fetus and the psychological burden on the parents should be factored into the risk-benefit evaluation $(2 /+00)$.

\section{NEONATAL SCREENING}

1.1. Benefits of $\mathrm{CH}$ screening

1.2. Analytical methodology and effectiveness of $\mathrm{CH}$ screening strategies

1.3. Postscreening strategies in special categories of neonates at risk of $\mathrm{CH}$

\subsection{Benefits of $\mathrm{CH}$ screening}

\section{Summary}

- Early detection and treatment of $\mathrm{CH}$ through neonatal screening prevent irreversible neurodevelopmental delay and optimize its developmental outcome $(1 /+++)$.

- Screening for $\mathrm{CH}$ should be introduced worldwide $(1 /+++)$.

Evidence. Neonatal screening for $\mathrm{CH}$ has almost eliminated the profound negative effects of $\mathrm{TH}$ deficiency on growth and neurodevelopment (cretinism) in those countries where it has been established. Improved developmental outcomes were already reported a few years after the start of neonatal screening $(3,4)$, and justified its economic costs by clearly outweighing the costs of providing health and educational care for individuals with neurodevelopmental damage due to $\mathrm{CH}(5)$.

Despite the benefits of neonatal screening, $70 \%$ of infants worldwide are born in areas that do not have access to neonatal screening (6). In addition, many of these infants are born in areas of endemic iodine deficiency, placing them at increased risk of TH deficiency.

\subsection{Analytical methodology and effectiveness of $\mathrm{CH}$ screening strategies}

\section{Summary}

- The incidence of $\mathrm{CH}$ partly depends on the screening strategy; based on data from a number of screening programs, the incidence of primary $\mathrm{CH}$ lies between 1 in 3000 and 1 in 2000; the highest reported incidence of central $\mathrm{CH}$ is $\sim 1$ in $16,000(1 /+++)$.

- The initial priority of neonatal screening for $\mathrm{CH}$ should be the detection of all forms of primary $\mathrm{CH}-$ mild, moderate, and severe; the most sensitive test for detecting primary $\mathrm{CH}$ is measurement of $\mathrm{TSH}(1 /+++)$. 
- When financial resources are available, we recommend adding measurement of total or fT4 to TSH, to screen for central $\mathrm{CH}(2 /++0)$.

Evidence. Since the introduction of neonatal screening for $\mathrm{CH}$ in the late 1970s, using total T4 plus, or followed by $\mathrm{TSH}$, gradually evolving into TSH only, its incidence and yield have also changed. An initial estimated incidence was revised from 1 in 7000 to $\sim 1$ in 4000 soon after the introduction of screening in the United Kingdom (7), probably reflecting more accurate data with detection of $\mathrm{CH}$ cases who were previously undiagnosed. Since then, the $\mathrm{CH}$ incidence has increased to between 1 in 3000 and 1 in 2000 .

This can be partly explained by the lowering of neonatal screening TSH cut-off values, resulting in the detection of newborns who would have been missed otherwise (false negatives) (8), but also in finding children with biochemically milder forms of $\mathrm{CH}$ (mostly with thyroid GIS) (9-11). However, the overall increase in the incidence of $\mathrm{CH}$ cannot be attributed solely to lower screening TSH cut-off values (12), and thus environmental, ethnic, and genetic factors should be considered, and all require further evaluation (13-18). For instance, the clinical expression of mutations in genes such as DUOX2/DUOXA2 varies widely between individuals and over time, with some patients requiring no treatment, and some having transient $\mathrm{CH}$. In contrast, DUOX gene mutations can be associated with worsening of thyroid fucntions in the first weeks of life (16). However, justification for screening and detecting biochemically less severe eventually transient $\mathrm{CH}$ cases require assessment of neurodevelopmental sequelae, but this has been proved difficult (19). Long-term outcome studies of the effect of LT4 treatment on prevention of neurodevelopmental delay in these patients will also be required.

Neonatal screening programmes were originally designed to detect primary $\mathrm{CH}$ by total $\mathrm{T} 4$ plus, or followed by TSH measurement, and later by measurement of only TSH, with optimal timing of samples at least 48 hours after birth. However, also measuring $\mathrm{T} 4 \pm \mathrm{T} 4$-binding globulin provides the potential to diagnose central $\mathrm{CH}$. Although slightly $>50 \%$ of neonates with central $\mathrm{CH}$ have moderate-to-severe $\mathrm{CH}$, that is, a first diagnostic fT4 concentration of $5-10 \mathrm{pmol} / \mathrm{L}$ or lower, and central $\mathrm{CH}$ is likely to be associated with other pituitary abnormalities, this diagnosis is often delayed $(20,21)$. Therefore, detection of central $\mathrm{CH}$ by neonatal screening has the potential to prevent the neurodevelopmental sequelae of TH deficiency and associated morbidities. The reported incidence of central $\mathrm{CH}$ detected through neonatal screening lies between 1 in 30,000 and 1 in 16,000, depending on the screening strategy (22-26). Although additional data on the true clinical benefits and false-positive rates are required, central $\mathrm{CH}$ is a potential candidate for neonatal screening.

Until 2019, only supportive therapy was available for patients with MCT8 deficiency. This changed when a clinical trial demonstrated that treatment with triiodothyroacetic acid (Triac) ameliorates key features of the peripheral thyrotoxicosis and might benefit brain development once treatment is commenced early in life (27). Therefore, early recognition of MCT8-affected children becomes of utmost importance through T4 and TSH neonatal screening eventhough the part of the fetal component of the disease that can be alleviated by Triac treatment remains to be determined.
Pitfalls in the newborn screening do exist and can be due to abnormal TH binding globulin, severe concomitant illnesses, as well as several drugs and autoantibodies $(24,28)$.

\subsection{Postscreening strategies in special categories of neonates at risk of $\mathrm{CH}$}

Summary

- Some groups of children, such as preterm or low birthweight and sick babies, pass their initial screening test but are at high risk for later development of mild $\mathrm{CH}$. For these groups, a postscreening strategy may be considered $(1 /+00)$.

- In patients with Down's syndrome, we recommend measuring TSH at the end of the neonatal period $(1 /++0)$.

- The initial screening in an affected twin may be normal; a strategy of a second screening should be considered. The nonaffected sibling of twins should be followed up for possible TSH elevation later in life $(2 /+00)$.

- Clinical suspicion of hypothyroidism, despite normal TSH in TSH-based screening programs, should prompt further evaluation for primary (rare cases of false-negative neonatal screening results) and central $\mathrm{CH}$, particularly in children with a family history of central $\mathrm{CH}(2 /+00)$.

Evidence. Babies with primary $\mathrm{CH}$ who are born premature or with low birthweight, or who are sick in the neonatal period may not be able to generate an adequate TSH response in the first weeks of life. Therefore, in TSH-based neonatal screening programs, their screening result may be false negative $(29,30)$. Maturation or recovery of the HPT axis with an increase in TSH occurs between the ages of 2 to 6 weeks of life, and many neonatal screening programs have revised recommendations for this group of infants $(29,31)$. In preterm newborns, the TSH surge and the blood levels of T4 and T3 are lower than those in term neonates. The immature HPT axis in the extreme preterm neonates is characterized by (i) a markedly attenuated TSH surge, (ii) a T4 decrease instead of an increase, and (iii) a clearly lower and shorter T3 increase within the first 24 hours of life. Interestingly, the T3 surge is observed as early as 1 hour postnatally, while the T4 surge only appeared at 7 hours after birth in infants born 28 to 30 gestational weeks and 31 to 34 gestational weeks (32). This observation may be explained by three factors: decreased T3 metabolism in the placenta, increased outer ring deiodination of $\mathrm{T} 4$, and increased thyroidal $\mathrm{T} 3$ release in response to the TSH surge. However, because the T3 increase at 1 hour after birth was independent of the TSH surge, and T4 peak values were reached only at 7 hours after birth in more mature infants, an abrupt loss of placental D3 activity is the most probable physiologic explanation for the observed rapid T3 increase followed by a slightly delayed T4 increase. Transient hypothyroxinemia of the preterm neonate is a frequent finding, often aggravated by general illness of the preterm neonate and it is due to an immature HPT function. So far, LT4 therapy of preterm hypothyroxinemia remains controversial and largescale randomized trials are necessary to provide more clarity on its potential impact or absence thereof. Even after diagnosis of $\mathrm{CH}$ in preterm infants, one needs to be aware of the high incidence of postnatal transient forms of $\mathrm{CH}$, emphasizing the need of diagnostic re-evaluation beyond infancy. The WolffChaikoff effect is only mature at the end of the third trimester. Premature neonates cannot protect themselves from excessive 
exposure to iodine overdose. Thus, the use of iodine-containing disinfectants is contraindicated in preterm babies, since exposure to topical iodine may cause transient neonatal hypo- or hyperthyroidism as summarized in a systematic review (33).

Although the concordance rate for $\mathrm{CH}$ in twins is low, twins are overrepresented in the $\mathrm{CH}$ population (34). Because of fetal blood mixing, the TSH concentration of an affected twin may be lower than expected and may escape detection in TSH-based screening $(34,35)$. Therefore, a low threshold for repeat TSH measurement is suggested, or a second screening should be considered in same-sex twins. In addition, the nonaffected twin should be followed up for possible TSH elevation later in life (36).

Down's syndrome is associated with a 14 to 21 times higher than expected incidence of $\mathrm{CH}$, and highly prevalent mild TSH elevation/subclinical hypothyroidism, especially in the first months to years of life (37-39). The probable cause of both phenomena is TD, probably related to the extra chromosome 21 and possibly to overexpression of the DYRK1A gene (40-43). Because many neonates with Down's syndrome have nonthyroidal illness due to (surgery for) cardiac or intestinal disease (44), TSH generation may be impaired resulting in a falsenegative neonatal screening result (in TSH-based screening programs). Therefore, additional measurement of TSH and fT4 around the age of 3 to 4 weeks should be considered.

In babies born into families affected with primary or central $\mathrm{CH}, \mathrm{fT} 4$ and TSH measurements are advised, even if TSH was normal in TSH-based screening programs. A delayed rise of TSH has been reported in newborns affected with defects in the DUOXs system (16). In central $\mathrm{CH}$, TSH is usually normal, but can be lower than normal or mildly elevated; only fT4 will contribute to the diagnosis $(25,45)$. In case of a known genetic cause, (even prenatal) genetic testing can prevent diagnostic delay.

Central $\mathrm{CH}$ should be considered in neonates with clinical manifestations of $\mathrm{CH}$ or congenital hypopituitarism, but a low, normal, or slightly elevated TSH concentration $(25,45,46)$. In addition, we recommend endocrine testing in all neonates with a familial history of central $\mathrm{CH}$, or signs or symptoms of congenital hypopituitarism, for example, micropenis with undescended testes, hypoglycemia, prolonged jaundice, or unexplained failure to thrive.

\section{DIAGNOSTICS AND CRITERIA FOR TREATMENT}

2.1. Biochemical criteria used in the decision to start treatment for $\mathrm{CH}$

2.2. Communication of abnormal neonatal screening and confimatory results

2.3. Imaging techniques in $\mathrm{CH}$

2.4. Associated malformations and syndromes

\subsection{Biochemical criteria used in the decision to start treatment for $\mathrm{CH}$}

\section{Summary}

- A newborn with an abnormal neonatal screening result should be referred to an expert center $(1 /++0)$.

- An abnormal screening result should be followed by confirmatory testing consisting of measurement of serum fT4 and TSH $(1 /++0)$.
- If the serum fT4 concentration is below and TSH clearly above the age-specific reference interval, then LT4 treatment should be started immediately $(1 /+++)$.

- If the serum TSH concentration is $>20 \mathrm{mU} / \mathrm{L}$ at confirmatory testing (approximately in the second week of life), treatment should be started, even if fT4 is normal (arbitrary threshold, expert opinion) $(2 /+00)$.

- If the serum TSH concentration 6-20 mU/L beyond the age of 21 days in a healthy neonate with an fT4 concentration within the age-specific reference interval, we suggest to either start LT4 treatment immediately and retest, off-treatment, at a later stage, or to withhold treatment but retest 1 to 2 weeks later and to re-evaluate the need for treatment (lack of evidence in favor or against treatment, this is an area of further investigation) $(2 /++0)$.

- In countries or regions where thyroid function tests are not readily available, LT4 treatment should be started if filter paper TSH concentration is $>40 \mathrm{mU} / \mathrm{L}$ (at the moment of neonatal screening; arbitrary threshold, expert opinion) $(2 /+00)$.

- If the serum fT4 is low, and TSH is low, normal or slightly elevated, the diagnosis central $\mathrm{CH}$ should be considered $(1 /++0)$.

- In neonates with central $\mathrm{CH}$, we recommend to start LT4 treatment only after evidence of intact adrenal function; if coexistent central adrenal insufficiency cannot be ruled out, LT4 treatment must be preceded by glucocorticoid treatment to prevent possible induction of an adrenal crisis $(2 /+00)$.

Evidence. Early detection and prompt treatment of $\mathrm{CH}$ (within the first 2 weeks of life) are essential to optimize the neurocognitive outcome, linear growth, the onset and progression of puberty, pubertal growth, and final height of affected neonates (47). All newborns with an abnormal neonatal screening result must be referred to an expert center for immediate thyroid function testing (TSH and fT4) to confirm the diagnosis of $\mathrm{CH}$.

Treatment is indicated if the serum TSH concentration is $>20 \mathrm{mU} / \mathrm{L}$ or fT4 is below the age-specific reference interval (48). In the latter case, severe, moderate, and mild forms can be classified according to fT4 concentrations, $<5,5-10$, and 10-15 pmol/L, respectively (1).

Whether neonates with mild hypothyroidism/hyperthyrotropinemia (i.e., diagnostic TSH concentrations between 6 and $20 \mathrm{mU} / \mathrm{L}$, but a normal fT4 concentration) benefit from LT4 treatment is still unclear $(49,50)$. Randomized controlled trials addressing this question have not been performed. The evolution of the TSH and fT4 concentrations and trend is instrumental in deciding whether to treat or not; the family history, thyroid imaging, and, if available, genetic analysis may be helpful in predicting the course of the thyroid function. In a large cohort study, Lain et al. found a worse neurocognitive outcome in children of school age with neonatal screening TSH concentrations between the 75th and 99.9th percentiles (51), while those with neonatal TSH values above the 99.9 th percentile $(12-14 \mathrm{mU} / \mathrm{L})$ had better cognitive development, possibly due to LT4 treatment. In contrast, in a Belgian cohort of children, there was no relationship between mild neonatal TSH elevation and neurodevelopment at the preschool age (52-54). 
In healthy neonates, it is generally suggested to evaluate thyroid function (TSH and fT4 measurement) every 1 to 2 weeks, and consider LT4 treatment when TSH is above, or fT4 is below the age-specific reference interval (48). Mild $\mathrm{CH}$ can be a permanent or transient condition. The family history, thyroid imaging, and genetic testing may be helpful to clarify the etiology and the need of (long-term) treatment (50).

In some coutries or regions, confirmatory thyroid function testing may not be readily available. In this scenario, LT4 treatment can be started when the neonatal screening TSH concentration is $\geq 40 \mathrm{mU} / \mathrm{L}$, without awaiting the confirmatory thyroid function test result. Such a value is highly suggestive of moderate-to-severe primary $\mathrm{CH}$ (55).

Central hypothyroidism is characterized by a low serum fT4 on combination with a low, normal, or slightly elevated TSH concentration. Other causes of this fT4-TSH combination are nonthyroidal illness, premature birth (with a correlation between severity and GA/birthweight), and certain forms of reduced sensitivity to $\mathrm{TH}$ (25). Central $\mathrm{CH}$ can be isolated or part of multiple pituitary hormone deficiency (MPHD) (56). In case of untreated adrenal insufficiency, LT4 treatment may cause an adrenal crisis. Therefore, LT4 treatment should be started only after a normal adrenal function test result or after glucocorticoid treatment has been started (45).

\subsection{Communication of abnormal neonatal screening and confirmatory results}

\section{Summary}

- An abnormal neonatal screening result should be communicated by an experienced professional (e.g., member of pediatric endocrine team, pediatrician, or general physician) either by telephone or face to face, and supplemented with written information for the family $(2 /+00)$.

- A confirmed $\mathrm{CH}$ diagnosis should be communicated face to face by a medical specialist $(2 /+00)$.

Evidence. In the organization of a (neonatal) screening program, both in industrialized and developing countries, communicating abnormal results is a key responsibility that should be carefully managed by trained personnel. Accurate prescreening information for families about the screening test and possible outcomes (e.g., false positives) improves participation and reduces possible parental anxiety. An abnormal neonatal screening result should be communicated quickly, but the way this should be done may differ, depending on biochemical severity and local circumstances (phone call directly to the family, web-based tool if available, etc.). The communication of a confirmed $\mathrm{CH}$ diagnosis should be carried out face to face by a medical specialist with sufficient knowledge of $\mathrm{CH}$; in case of language or cultural differences, deployment of a translator or (cultural) mediator is recommended. Taking time and using simple language to explain the implications and management of the diagnosis, and the importance of early detection and adequate LT4 treatment are essential. Written materials can be helpful but should not replace this face-toface discussion (57-59).

\subsection{Imaging techniques in $\mathrm{CH}$}

\section{Summary}

- In patients with a recent $\mathrm{CH}$ diagnosis, we strongly recommend starting $\mathrm{LT} 4$ treatment before conducting thyroid gland imaging studies $(1 /++0)$.

- We recommend imaging of the thyroid gland using either radioisotope scanning (scintigraphy) with or without the perchlorate discharge test, or US, or both $(1 /++0)$.

- X-ray of the knee may be performed to assess the severity of intrauterine hypothyroidism $(2 /+00)$.

Evidence. Although it does not change initial treatment, it is recommended to determine the etiology of $\mathrm{CH}$ at the time of diagnosis. However, this approach should never delay the start of treatment in newborns with $\mathrm{CH}$. Early determination of the cause of $\mathrm{CH}$ provides the family with a precise diagnosis (including visual evidence) and, with that, strong arguments that their child has a congenital disorder necessitating lifelong daily treatment. Furthermore, an early accurate diagnosis - in most cases achievable by dual imaging - abolishes the need for further diagnostic testing and re-evaluation of the cause later on. Finally, (dual) imaging can give direction to genetic counseling and testing, providing information about the risk of recurrence and a possible early diagnosis in future siblings.

Thyroid US. US is an important diagnostic tool for determining the presence of the thyroid gland and, when present, its location, size, and echotexture. US, however, is less accurate than radionuclide scan for detection of an ectopic thyroid gland. It is a noninvasive nonirradiating costeffective imaging technique, but highly observer dependent. Thyroid volume in newborns varies from $0.84 \pm 0.38$ to $1.62 \pm 0.41 \mathrm{~mL}(60-62)$, without significant changes during the first 3 weeks of life (63). Thyroid size can be influenced by (long-term) TSH suppression during LT4 treatment. In that case, TSH should be measured at the time of the US so that thyroid size can be correctly interpreted. Thyroid US should be performed by an expert.

Thyroid scintigraphy. Scintigraphy is the most accurate diagnostic test for determining the etiology of $\mathrm{CH}$, especially in case of TD. Technetium-99m $\left({ }^{99 \mathrm{~m}} \mathrm{Tc}\right)$ and iodine$123\left({ }^{123} \mathrm{I}\right)$ are both captured by sodium (Na)-iodide symporter (NIS) at the basal side of thyrocytes and are both suitable for imaging. ${ }^{99 \mathrm{~m}} \mathrm{Tc}$ is more widely available, less expensive, faster in use (image acquisition 15 minutes after administration), and has a shorter half-live than ${ }^{123} \mathrm{I} .{ }^{99 \mathrm{~m}} \mathrm{Tc}$ is not organified, it is, therefore, difficult to provide quantification of the radionuclide uptake using ${ }^{99 \mathrm{~m}} \mathrm{Tc}$. Images are of lower quality than with ${ }^{123} \mathrm{I}$. The latter isotope needs later image acquisitions (at 2-3, and 24 hours), but provides more contrast and adds information about organification process, allowing perchlorate discharge testing when the thyroid is eutopic $(64,65)$. Furthermore, it exposes infants to a lower dose of whole-body irradiation than ${ }^{99 \mathrm{~m}} \mathrm{Tc}(3-10 \mu \mathrm{Ci} / \mathrm{kg}$ vs. $50-250 \mu \mathrm{Ci} / \mathrm{kg}$ body weight) $(66,67)$.

When the thyroid is present and normally located, and if sodium perchlorate is available, perchlorate discharge testing can be performed to study the iodine retention capacity of the 
thyroid gland. Sodium perchlorate is administred and thyroid activity is measured before and 1 hour afterward. The perchlorate discharge test is considered positive when discharge of ${ }^{123} \mathrm{I}$ is more than $10 \%$ of the administered dose. Together with serum thyroglobulin measurement, the perchlorate discharge test provides useful information for targeted genetic testing to diagnose the various forms of $\mathrm{CH}$ caused by dyshormonogenesis (1). One pitfall of scintigraphy is lack of isotope uptake despite the presence of thyroid tissue. This can be due to TSH suppression at the time of the scintigraphy (when performed beyond 5 to 7 days after the start of LT4 treatment), previous iodine exposure, maternal blocking TSH receptor antibodies, and mutations in genes affecting iodine uptake (NIS) or TSH receptor (TSHR) defects. In these cases, thyroid US should be performed to demonstrate the presence or absence of thyroid tissue. When treatment-related TSH suppression is the cause, and treatment cannot be interrupted, thyroid scintigraphy and perchlorate discharge testing can also be performed after recombinant human TSH administration (68).

Dual imaging. The combination of thyroid US and scintigraphy provides high-resolution anatomical (US) and functional (scintigraphy) information, allowing to distinguish between permanent and possible transient $\mathrm{CH}(64,67,69)$. Each technique compensates for limitations and pitfalls of the other. Dual imaging is particularly effective in confirming athyreosis (when scintigraphy shows absence of isotope uptake) and detecting thyroid ectopy $(65,67)$.

$X$-ray of the knee. At birth, bone maturation is delayed in the majority of patients with severe $\mathrm{CH}$ and is considered a disease severity parameter. It has been shown to correlate with neurodevelopmental outcome (70), educational level (71), hearing impairment (72), and can be assessed by performing a X-ray of the knee (presence or absence of the femoral and tibial epiphyses). LT4 treatment normalizes bone maturation within the first year of life $(70,73)$. Although disease severity can be derived from the first diagnostic fT4 and TSH concentrations, a knee X-ray can be performed as an additional parameter reflecting the severity of intrauterine hypothyroidism.

\subsection{Associated malformations and syndromes}

\section{Summary}

- All neonates with $\mathrm{CH}$ should be examined carefully for dysmorphic features suggestive for syndromic $\mathrm{CH}$, and for congenital malformations (particularly cardiac) $(1 /+++)$.

Evidence. Permanent $\mathrm{CH}$ can be isolated or syndromic. Careful clinical examination during the first days of life is, therefore, necessary to detect dysmorphic features suggestive of a syndrome. Syndromic $\mathrm{CH}$ is mostly caused by mutations in genes encoding transcription factors or involved in early thyroid development. The Bamforth-Lazarus syndrome (OMIM No. 241850) is characterized by TD (mainly athyreosis or severe hypoplasia), cleft palate, and spiky hair with or without bilateral choanal atresia or bifid epiglottis, and is due to biallelic mutations in the FOXE1 gene (74). Another example of syndromic $\mathrm{CH}$ that can be recognized during neonatal period or early infancy is the brain-lung-thyroid (BLT) syndrome (OMIM No. 610978) due to NKX2-1 haploinsufficiency, characterized by various types of $\mathrm{CH}$, infant respiratory distress syndrome, and benign hereditary chorea $(75,76)$. Other examples of syndromic $\mathrm{CH}$ are Alagille syndrome type 1 (OMIM No. 118450) with thyroid in situ, liver (bile duct hypoplasia), and cardiac malformations (77); Williams-Beuren (OMIM No. 194050) and DiGeorge syndromes (OMIM No. 188400) with a high prevalence of thyroid hypoplasia (50-70\%) and subclinical hypothyroidism (25-30\%) (78,79); and Kabuki (80) and Johanson-Blizzard syndromes (81) with a eutopic thyroid gland. Pendred syndrome due to mutations in the SLC26A4 gene (OMIM No. 274600), with or without goiter, should be considered in case of congenital sensorineural hearing loss. Finally, the prevalence of congenital malformations, particularly cardiac defects, including septal defects, and renal abnormalities (82) is higher in individuals with $\mathrm{CH}$ than in the general population, with differences in prevalence between studies (83-89); indeed, the reported frequency of cardiac defects in $\mathrm{CH}$ is between $3 \%$ and $11 \%$, compared with $0.5 \%$ to $0.8 \%$ in all live births. For Down's syndrome, see Section 1.3.

\section{TREATMENT AND MONITORING OF CH}

3.1. Starting treatment for primary $\mathrm{CH}$

3.2. Monitoring treatment in primary $\mathrm{CH}$

3.3. Treatment and monitoring of central $\mathrm{CH}$

3.4. Diagnostic re-evaluation of thyroid function beyond the first 6 months of life

3.5. Treatment and monitoring of pregnant women with $\mathrm{CH}$

\subsection{Starting treatment for primary $\mathrm{CH}$}

\section{Summary}

- LT4 alone is recommended as the medication of choice for the treatment of $\mathrm{CH}(1 /++0)$.

- LT4 treatment should be started as soon as possible, not later than 2 weeks after birth or immediately after confirmatory (serum) thyroid function testing in neonates in whom $\mathrm{CH}$ is detected by a second routine screening test $(1 /++0)$.

- The LT4 starting dose should be up to $15 \mu \mathrm{g} / \mathrm{kg}$ per day, taking into account the whole spectrum of $\mathrm{CH}$, ranging from mild to severe $(1 /++0)$.

- Infants with severe $\mathrm{CH}$, defined by a very low pretreatment serum fT4 $(<5 \mathrm{pmol} / \mathrm{L})$ or total T4 concentration in combination with elevated TSH (above the normal range based on time since birth and GA), should be treated with the highest starting dose $(10-15 \mu \mathrm{g} / \mathrm{kg}$ per day) $(1 /++0)$.

- Infants with mild CH (fT4>10 pmol/L in combination with elevated TSH) should be treated with the lowest initial dose $(\sim 10 \mu \mathrm{g} / \mathrm{kg}$ per day); in infants with pretreatment fT4 concentrations within the age-specific reference interval, an even lower starting dose may be considered (from 5 to $10 \mu \mathrm{g} / \mathrm{kg})(1 /++0)$.

- LT4 should be administered orally, once a day $(1 /++0)$.

- The evidence favoring brand versus generic LT4 is mixed, but based on personal experience/expert opinion, we recommend brand rather than generic $(2 /++0)$. 
Evidence. There are no randomized clinical trials that support a specific treatment approach in $\mathrm{CH}$ with highquality evidence. Since the first enthusiastic reports on the successful treatment of "sporadic cretinism" with thyroid extracts derived from animal thyroid glands, all further adaptations and improvements have been based on retrospective or prospective observational studies only. However, today a large series of such cohort studies is available that were undertaken to correlate final outcome to different treatment strategies. Initially somatic development in terms of growth and puberty was studied, but later on cognitive outcome- the most precious, but also vulnerable developmental outcome-became the focus of such studies. The highest level of evidence was gained by those studies that assessed the cognitive outcome (intelligence quotient [IQ]) in individuals with $\mathrm{CH}$ and unaffected sibling controls. Together, the available data allow for reliable conclusions and recommendations. One such conclusion is that one can expect a favorable outcome in most children with $\mathrm{CH}$ who were given the "right" treatment. In this respect, numerous outcome studies point to a strong impact of two (main) factors that influence cognitive outcome: the age at start of LT4 treatment and the LT4 starting dose.

Age at start of treatment and starting dose. Bearing in mind that these factors were not studied systematically, one can only deduce conclusions and recommendations from observational studies. Therefore, the recommendations on the optimal age at start of LT4 treatment and the optimal starting dose are deduced from reasonably powered studies that eventually demonstrated no difference in cognitive outcome between individuals with $\mathrm{CH}$ and unaffected siblings. So far only two such studies are available. Initially, two outcome studies in young adult $\mathrm{CH}$ patients and sibling controls showed an IQ gap of eight points. In these observational studies, treatment was started at an average age of 24 days and with average LT4 dose $<10 \mu \mathrm{g} / \mathrm{kg}$ per day. The first study that reported no gap comparing $44 \mathrm{CH}$ and 53 unaffected sibling controls with a median age at time of testing of 9 years was from New Zealand and published in 2013 (90). Patients were treated with LT4 from a mean age of 9 days with a starting dose between 10 and $15 \mu \mathrm{g} / \mathrm{kg}$ depending on $\mathrm{CH}$ severity. Neonates with athyreosis were treated with $15 \mu \mathrm{g} / \mathrm{kg}$ per day. TSH normalized within a median of 14 days after diagnosis. Power calculation predicted that the number of patients and siblings would be sufficient to detect a difference of 5.2 IQ point. There was no significant difference between the tested patients and siblings.

The second study reporting no gap comparing $76 \mathrm{CH}$ patients and 40 sibling controls was from Berlin and was published in 2018 (91). The treatment approach resembled the New Zealand approach with a median age at diagnosis of 8 days, a mean LT4 starting dose of $13.5 \mu \mathrm{g} / \mathrm{kg}$ per day, and TSH normalizing within a median time of 15 days. In contrast to the New Zealand study, the mean ages of the patients and controls were 18.1 and 19.8 years, respectively. There was no significant difference in overall IQ (102.5 vs. 102.5), nor were there differences in other (cognitive) tests of attention, memory, fine motor skills, quality-of-life scores, and in anthropometric measurements. In addition, there was no negative effect of episodes of overtreatment in terms of a suppressed TSH. Even in the children with the highest number of episodes of TSH suppression, IQ and other outcome parameters did not differ.

Based on the evidence from four studies reporting sibling-controlled cognitive outcome data, one can deduce and conclude that a even a child with severe $\mathrm{CH}$ can reach a normal IQ that does not differ from unaffected siblings, if LT4 treatment is started before the age of 10 days and the starting dose is at least $10 \mu \mathrm{g} / \mathrm{kg}$, with $15 \mu \mathrm{g} / \mathrm{kg}$ in the most severe forms. More precise values for the optimal age at start of LT4 treatment or the starting dose leading to such a favorable outcome cannot be given since this has not been systematically studied. However, in a meta-analysis included in the Berlin study comparing IQ differences between severe and mild $\mathrm{CH}$ cases with respect to the starting dose revealed that this difference can only be overcome with a starting dose of at least $10 \mu \mathrm{g} / \mathrm{kg}$, but not lower than that.

Hormone preparations and administration. Since there are only a few studies on the effect of different hormone preparations or methods of administration available, recommendations are based on the results of the previously mentioned studies. Those studies that reported a normal cognitive outcome did either use crunched LT4 tablets dissolved in water or breast milk administered through a spoon, or liquid LT4 preparations (both administered orally). In none of the studies T3 was administered. Because the cognitive outcomes in these studies were favorable, it is recommended to use only LT4, administered as just described. The expert panel recognizes that crushing tablets is an off-label procedure, but that it has been done this way succesfullly for many years. Clinical experience suggests that the bioavailability of liquid LT4 preparations is higher than tablets, with a possible risk of overtreatment if tablet doses are used. The higher bioavailability may also have dosing consequences for changing medication from tablets to liquid, and the other way around. In addition, $\mathrm{CH}$ patients treated with liquid LT4 may need more frequent fT4 and TSH measurements, and dose adjustments during their first months of life $(92,93)$. If intravenous treatment is necessary, the (starting) dose should be no more than $80 \%$ of the oral dose; subsequently, the dose should be adjusted guided by fT4 and TSH measurements. It should be stressed that only pharmaceutically produced medication should be prescribed. This applies to both tablets and liquid LT4 preparations. Brand rather than generic LT4 tablets should be used, particularly in severe $\mathrm{CH}$ and in infants (94). The expert panel is against the use of compounded solutions or suspensions. Finally, parents should be provided with written instructions about LT4 treatment.

\subsection{Monitoring treatment in primary $\mathrm{CH}$}

Summary

- We recommend measurement of serum fT4 and TSH concentrations before, or at least 4 hours after the last (daily) LT4 administration (1/++0).

- We recommend evaluation of fT4 and TSH according to age-specific reference intervals $(1 /++0)$.

- The first treatment goal in neonates with primary $\mathrm{CH}$ is to rapidly increase the circulating amount of thyroid 
hormone, reflected by normalization of serum TSH; therafter, TSH should be kept within the reference interval.

- If TSH is in the age-specific reference interval, fT4 concentrations above the upper limit of the reference interval can be accepted and recommend maintaining the same LT4 dose $(1 /++0)$.

- Any reduction of the LT4 dose should not be based on a single higher than normal fT4 concentration, unless TSH is suppressed (i.e., below the lower limit of the reference interval) or there are signs of overtreatment (e.g., jitteriness or tachycardia) $(1 /++0)$.

- The first clinical and biochemical follow-up evaluation should take place 1 to 2 weeks after the start of LT4 treatment ( 1 week at the latest in case of a starting dose close to $15 \mu \mathrm{g} / \mathrm{kg}$ per day or an even higher dose) $(1 /+00)$.

- Subsequent (clinical and biochemical) evaluation should take place every 2 weeks until complete normalization of serum TSH is achieved; therafter, the evaluation frequency can be lowered to once every 1 to 3 months until the age of 12 months $(1 /+00)$.

- Between the ages of 12 months and 3 years, the evaluation frequency can be lowered to every 2 to 4 months; thereafter, evaluations should be carried out every 3 to 6 months until growth is completed $(1 /+00)$.

- If abnormal fT4 or TSH values are found, or if compliance is questioned, the evaluation frequency should be increased $(2 /+00)$.

- After a change of LT4 dose or formulation, an extra evaluation should be carried out after 4 to 6 weeks $(2 /+00)$.

- Adequate treatment throughout childhood is essential, and long-term under- or overtreatment, that is, TSH concentrations above or below the reference interval, should be avoided (1/++0).

- In contrast to adults, in neonates, infants and children LT4 can be administered together with food (but with avoidance of soy protein and vegetable fiber); more important, LT4 should be administered at the same time every day, also in relation to food intake. This approach can improve compliance, and ensures as consistent as possible LT4 absorption and as good as possible LT4 dose titration $(2 /+00)$.

- In case of an unexpected need for LT4 dose increase, reduced absorption or increased metabolization of $\mathrm{T} 4$ by other disease (e.g., gastrointestinal), food, or medication should be considered $(2 /+00)$; noncompliance may be the most frequent cause, especially in teenagers and adolescents.

\section{Evidence}

Shortly after the start of LT4 treatment. Repeated measurement of serum fT4 and TSH, and clinical assessment (especially for signs of overtreatment when using the highest starting dose) are the backbone of monitoring LT4 treatment in patients with primary $\mathrm{CH}$ (95-97). TSH normalizes slower than fT4. Therefore, the first treatment goal is as rapid as possible normalization of fT4. Since fT4 reflects the unbound biologically active form of T4, measurement of fT4 is preferred to total T4 (98). The second treatment goal is normalization of TSH within 4 weeks. Consequently, fT4 (or total T4) should guide dosing until TSH reaches the age- specific reference interval (99). Rapid normalization of TSH and keeping fT4 in the upper half of the age-specific reference interval have been shown to optimize the neurodevelopmental outcome $(90,100-102)$.

Follow-up after the first weeks of LT4 treatment. There is no evidence for a one optimal follow-up scheme. Recent studies focusing on optimization of biochemical thyroid function testing suggest the importance of frequent laboratory monitoring and dose adjustment during the first year of life. Findings in these studies were that (i) patients with severe $\mathrm{CH}$ (athyreosis and dysgenesis vs. dyshormonogenesis, with high TSH values at diagnosis) need more dose adjustments during the first year of life $(103,104)$; (ii) the highest doses within the recommended range of $10-15 \mu \mathrm{g} / \mathrm{kg}$ per day resulted in more dose adjustments because of hyperthyroxinemia (105-107); and (iii) monthly thyroid function testing led to frequent dose adjustments during the first year of life (75\% at 0-6 months of age, and $36 \%$ at $7-12$ months of age) (97). However, in none of these studies neurodevelopmental outcome data were available, the most important long-term treatment goal in $\mathrm{CH}$. With this in mind, the follow-up schemes that were chosen in the studies that reported normal IQ outcomes can be used as recommendation. In the New Zealand and the Berlin studies, treatment effectiveness in terms of normalization of serum parameters was tested weekly after the start of treatment until they normalized $(90,91)$. Thereafter, in New Zealand, blood tests were done monthly during the first year and bimonthly during the second year, and every 3 months in the Berlin study. Obviously, follow-up schemes have to be personalized according to parents' capabilities and compliance.

The main biochemical target parameter in primary $\mathrm{CH}$ is TSH. The Berlin study reported on all obtained serum parameters during the first 2 years of life in all treated children. This revealed that when TSH was within the reference interval, T4 was often elevated but T3 was normal. Noteworthy, also in adult patients with severe acquired hypothyroidism, a higher serum fT4 is necessary to reach normal TSH concentrations. This may be due to lack of thyroidal production of $\mathrm{T} 3$ that needs to be compensated by a higher fT4 concentration.

Data on the effects of clearly increased serum (f)T4 concentrations are scarce. In two studies, long-term follow-up after periods of overtreatment during the first 2 years of life suggested a decreased IQ at the age of 11 years, and an increased rate of attention deficit hyperactivity disorder $(108,109)$. Earlier studies suggested adverse effects on attention span (110). However, Aleksander et al. showed no IQ differences between patients and siblings despite comparable periods of overtreatment (91). As long as there is no evidence for a possible negative effect of periods of overtreatment, dose reduction in case of an elevated fT 4 should only be done after a second fT4 measurement, unless TSH is suppressed. Besides overtreatment, "resetting" of the hypothalamuspituitary-thyroid feedback axis after intrauterine hypothyroidism has been proposed as a possible mechanism, especially in patients younger than 12 months $(24,111)$. Persistence of such mild hypothalamus-pituitary resistance has been reported in adult $\mathrm{CH}$ patients compared with patients with acquired hypothyroidism (112).

In summary, there is no definitive evidence for one optimal follow-up scheme based on studies with cognitive 
outcome as the main parameter. However, a normal cognitive outcome has been achieved with monthly and bimonthly, and with 3-monthly controls during the first 2 to 3 years of life, after TSH normalization in the first weeks after diagnosis. Furthermore, patients with the most severe forms of $\mathrm{CH}$ and the highest range of the recommended LT4 starting dose are at an increased risk for frequent dose adjustments in the first year of life because of elevated fT4 levels. Since the long-term neurological consequences of hyperthyroxinemia/periods of overtreatment are still not clarified, the follow-up frequency should be individualized with more controls in case of suboptimal fT4 or TSH values. After dose adjustment, a next control is recommended 4 to 6 weeks later (113). Finally, adolescence and the period of transition to adult care are critical periods. Individualized follow-up schemes should be drawn up to assure normal growth and puberty in the adolescent, and fertility in the young adult (114).

Adverse effects of LT4. Adverse effects of long-term LT4 treatment are rare or absent if adequately prescribed. Cases of pseudotumor cerebri or craniosynostosis have been described $(115,116)$. However, relative macrocrania at the age of 18 months, but without any case of craniosynostosis, was reported in a cohort of $45 \mathrm{CH}$ patients with documented fT4 concentrations above the reference interval during their first 6 to 9 months of life (117). In one cohort of young adults with $\mathrm{CH}$, cardiovascular abnormalities were reported (impaired diastolic dysfunction and exercise capacity, and increased intima media thickness, IMT); however, the clinical relevance of these findings remains unknown. Moreover, in a large nationwide study, standardized mortality ratio in patients with $\mathrm{CH}$ was not increased for diseases of the circulatory system (87).

Cardiac insufficiency. LT4 has clear positive ino- and chronotropic effects on the heart. In newly diagnosed $\mathrm{CH}$ in newborns with congenital heart disease and impending heart failure, we therefore recommend to apply a lower LT4 starting dose-approximately $50 \%$ of the recommended dose-and to increase it guided by serum fT4 and TSH measurement, and the infant's clinical condition.

Impaired bioavailability by diseases, drugs, or food. LT4 is mainly absorbed in the proximal small intestine. Undiagnosed or untreated celiac disease will reduce LT4 absorption. Children with short bowel syndrome will also have reduced absorption (118). Recently, rectal administration of LT4 was been shown to be effective in a child with this condition (119). Increased type 3 deiodinase activity in large hemangiomas can cause increased metabolic clearance of administered LT4 and, with that, necessitate a higher LT4 dose (120-122). Bioavailability of LT4 can also be reduced by concomitant use of other medication. For example, proton pump inhibitors, calcium or iron, will decrease absorption, while antiepileptic medication (phenobarbital, phenytoin, and carbamazepine) and rifampicin will increase its metabolic clearance. Interactions need to be considered and can sometimes be overcome by avoiding concomitant ingestion $(123,124)$.

While in adults the recommended LT4 intake moment is 30-60 minutes before intake of food $(125,126)$, such a recommendation is difficult to realize in infants (123). Prag- matically, LT4 should be administered at a fixed time with an equal interval to food intake every day to have a constant as possible LT4 absorption and, with that, as good as possible LT4 dose titration. Soy containing food products have been repeatedly shown to inhibit LT4 absorption in children with $\mathrm{CH}(127,128)$.

\subsection{Treatment and monitoring of central $\mathrm{CH}$}

- In severe forms of central $\mathrm{CH}$ (fT4 $<5 \mathrm{pmol} / \mathrm{L}$ ), we also recommend to start LT4 treatment as soon as possible after birth at doses like in primary $\mathrm{CH}$ (at least $10 \mu \mathrm{g} / \mathrm{kg}$ per day, see Section 3.1), to bring fT4 rapidly within the normal range $(1 /++0)$.

- In milder forms of central $\mathrm{CH}$, we suggest starting treatment at a lower LT4 dose $(5-10 \mu \mathrm{g} / \mathrm{kg}$ per day) to reduce the risk of overtreatment $(1 /++0)$.

- In newborns with central $\mathrm{CH}$, we recommend monitoring treatment by measuring fT4 and TSH according to the same schedule as for primary $\mathrm{CH}$; serum fT4 should be kept above the mean/median value of the age-specific reference interval; if TSH is low before treatment, subsequent TSH determinations can be omitted $(1 /+00)$.

- When under- or overtreatment is suspected in a patient with central $\mathrm{CH}$, then TSH or fT3 or T3 can be measured $(1 /+00)$.

- When fT4 is around the lower limit of the reference interval, then undertreatment should be considered, particularly if TSH $>1.0 \mathrm{mU} / \mathrm{L}(1 /+00)$.

- When serum fT4 is around or above the upper limit of the reference interval, then overtreatment should be considered (assuming that LT4 has not been administered just before blood withdrawal), particularly if associated with clinical signs of thyrotoxicosis, or a high (f)T3 concentration $(1 /+00)$.

Evidence. Just like primary $\mathrm{CH}$, treatment of central $\mathrm{CH}$ consists of daily administration of LT4 (orally; tablets or liquid dosage form). The biggest differences between the treatment of primary and central $\mathrm{CH}$ are in the monitoring of treatment-with serum fT4 (instead of TSH) being the most important parameter-and in the LT4 starting dose. Important to realize is that in central $\mathrm{CH}$, a low TSH concentration does not point to overtreatment.

The (biochemical) LT4 treatment aim is bringing and keeping the fT4 concentration in the upper half of the agespecific fT4 reference interval. Although randomized clinical trials testing this approach in children are lacking, studies in adults give some support $(129,130)$.

Central $\mathrm{CH}$ can be a severe condition (fT4 at diagnosis $<5 \mathrm{pmol} / \mathrm{L}$ ), but most cases can be classified as mild to moderate (fT4 at diagnosis 5-15 pmol/L) $(20,131)$. Although studies investigating the optimal starting dose in central $\mathrm{CH}$ are lacking, clinical experience has taught that an LT4 starting dose of $10-15 \mu \mathrm{g} / \mathrm{kg}$ in mild-to-moderate cases quickly results in supraphysiological fT4 concentrations. So, with exception of severe cases, a lower starting dose that is $5-10 \mu \mathrm{g} / \mathrm{kg}$ is advisable.

With regard to the treatment monitoring frequency, the schedule for primary $\mathrm{CH}$ should be followed. 


\subsection{Diagnostic re-evaluation of thyroid function beyond the first 6 months of life}

\section{Summary}

- When no definitive diagnosis of permanent $\mathrm{CH}$ was made in the first weeks or months of life, then reevaluation of the HPT axis after the age of 2 to 3 years is indicated, particularly in children with a GIS, and in those with presumed isolated central $\mathrm{CH}(1 /++0)$.

- For a precise diagnosis, LT4 treatment should be phased out over a 4 to 6 weeks period or just stopped, and full re-evaluation should be carried out after 4 weeks, consisting of (at least) fT4 and TSH measurement.

- If primary hypothyroidism is confirmed (TSH $\geq 10 \mathrm{mU} / \mathrm{L}$ ), consider thyroid imaging and, if possible, genetic testing; if central $\mathrm{CH}$ is likely (fT4 below the lower limit of the reference interval in combination with a low normal of only mildly elevated TSH), consider evaluating the other anterior pituitary functions and genetic testing.

- If TSH is above the upper limit of the reference interval but $<10 \mathrm{mU} / \mathrm{L}$ (primary $\mathrm{CH}$ ) or fT4 just above the lower limit of the reference interval (central $\mathrm{CH}$ ), then continue withdrawal and retest in another 3 to 4 weeks $(1 /++0)$.

- If a child with no permanent $\mathrm{CH}$ diagnosis and a GIS requires an LT4 dose $<3 \mu \mathrm{g} / \mathrm{kg}$ per day at the age of 6 months, then re-evaluation can be done already at that time $(1 /++0)$.

- We recommend avoiding iodine as an antiseptic during peri- and neonatal period, as it can cause transient $\mathrm{CH}$ $(1 /++0)$.

Evidence. In recent years, the prevalence of transient $\mathrm{CH}$ has steadily increased. In a number of studies, factors have been identified that increase the likelihood of transient disease, such as sex (more often in boys) $(132,133)$, low birthweight $(134,135)$, neonatal morbidity requiring intensive care (135), race/ethnicity (more often in nonwhite patients) (14), and less severe $\mathrm{CH}$ at diagnosis (assessed by screening TSH, or diagnostic TSH or fT4) $(8,132,133,136-141)$. In contrast, factors such as prematurity $(11,142,143)$, other congenital abnormalities (141), a family history of thyroid disease (142), abnormal thyroid morphology (thyroid hypoplasia at diagnosis) (142), TSH elevation $>10 \mathrm{mU} / \mathrm{L}$ after the age of 1 year (when infants outgrow the LT4 dose), and a higher LT4 dose requirement at 1 to 3 years of age are associated with permanent $\mathrm{CH}$ (with conflicting results between studies for the factor dose requirement) $(132,133,136$ 140,143-147). Recent studies have shown that early treatment withdrawal to assess the necessity of further treatment can be considered and done from the age of 6 months onward, particularly in patients with a GIS, a negative first-degree family history of $\mathrm{CH}$, or in those requiring a low LT4 dose. Saba et al. (148) investigated 92 patients with $\mathrm{CH}$ and a GIS and found 49 of them $(54 \%)$ to have transient $\mathrm{CH}$. In this study, the optimal LT4 dose cut-off values for predicting transient $\mathrm{CH}$ at the ages of 6 and 12 months were 3.2 and $2.5 \mu \mathrm{g} / \mathrm{kg}$ per day, respectively, with a sensitivity of $71 \%$ at both time points, and a specificity of $79 \%$ and $78 \%$ at the ages of 6 and 12 months, respectively (with values below these thresholds considered predictive of transient $\mathrm{CH}$ ). In the study by Oron et al. (149), 17 out of 84 patients with a GIS (20\%) turned out to have transient CH. The optimal LT4 dose cut-off values at the age of 6 months were $2.2 \mu \mathrm{g} / \mathrm{kg}$ per day, with a sensitivity of $90 \%$ and a specificity of $57 \%$. Both studies highlight the need for careful clinical and biological monitoring to identify children who do not require long-term treatment.

Medication that interferes with thyroid function, in particular iodine and iodomimetics, may result in transient but profound hypothyroidism (150). The use of iodine as a skin antiseptic, such as povidone-iodine (PVP-1), is therefore not recommended in obstetrics and neonatology, since it reaches the fetal or neonatal thyroid gland easily, causing transient hypothyroidism (through skin and placenta in mothers, and skin in neonates) $(29,151,152)$. This may be more profound in premature born babies, as escape from the Wolff Chaikoff effect does not mature until term. Mothers should be asked about consumption of iodine-rich nutritional food or supplements, which can also induce transient $\mathrm{CH}$ (153).

\subsection{Treatment and monitoring of pregnant women with $\mathrm{CH}$}

\section{Summary}

- In women with $\mathrm{CH}$ who are planning pregnancy, we strongly recommend optimization of LT4 treatment; in addition, these women should be counseled regarding the higher need for LT4 during pregnancy $(1 /++0)$.

- fT4 (or total T4) and TSH levels should be monitored every 4 to 6 weeks during pregnancy, aiming at TSH concentrations in accordance with current guidelines on treatment of hypothyroidism during pregnancy, that is, $<2.5 \mathrm{mU} / \mathrm{L}$ throughout gestation in patients treated with LT4 $(1 /+00)$.

- In pregnant women with central $\mathrm{CH}$, the LT4 doses should be increased aiming at an fT4 concentration above the mean/median value of the trimester-specific reference interval $(1 /+00)$.

- After delivery, we recommend lowering the LT4 dose to preconception dose; additional thyroid function testing should be performed at $\sim 6$ weeks postpartum $(1 /++0)$

- All pregnant women should ingest $\sim 250 \mu \mathrm{g}$ iodine per day $(1 /++0)$.

Evidence. Optimal management of pregnant women with $\mathrm{CH}$ requires knowledge and understanding of the normal physiological changes. In early pregnancy, before and during the development of the functioning fetal thyroid gland, the fetus depends on TH supply by the mother, requiring an optimal iodine status. Indeed, since the fetal thyroid gland is not functionally matured before weeks 18-20 of pregnancy, the fetus largely depends on the supply of maternal T4 during the early stages of intrauterine brain development, making fT4 the most important hormone for the fetus. During the second half of pregnancy, fetal thyroid hormones are both from maternal and fetal origin. Overt and subclinical maternal hypothyroidism have been associated with adverse pregnancy outcomes as well as with neurodevelopmental deficits in the offspring, particularly if the dysfunction occurs early in pregnancy. With respect to adverse pregnancy outcomes, maternal $\mathrm{CH}$ is associated with an increased risk of 
gestational hypertension, emergency cesarean section, induced labor for vaginal delivery, and preterm delivery $(154,155)$. TSH $\geq 10 \mathrm{mU} / \mathrm{L}$ during the first 3 to 6 months of pregnancy is associated with a higher risk of preterm delivery and fetal macrosomia. These associations were not found in women with satisfactory control of hypothyroidism, that is, TSH $<10 \mathrm{mU} / \mathrm{L}$. Yet, these women did have a higher risk of induced labor for vaginal delivery (154). Children born to mothers with $\mathrm{CH}$ were found to have a higher risk of poor motor coordination, but not of other developmental domains such as mobility, communication, and motor and language skills. However, children born to mothers with TSH $\geq 10 \mathrm{mU} / \mathrm{L}$ were more likely to have low motor or communication skills scores. Yet, it remains unclear whether these adverse effects modify subsequent neurodevelopment $(156,157)$. During pregnancy, TH requirement increases and most LT4-treated women require a dose increase up to $30 \%$. Women with athyreosis, the most severe form of $\mathrm{CH}$, require the highest doses and treatment should aim to keep TSH concentrations $<2.5 \mathrm{mU} / \mathrm{L}$ throughout pregnancy $(154,155,158)$. Therefore, careful monitoring of LT4 treatment of pregnant women with hypothyroidism is extremely important.

\section{OUTCOMES OF NEONATAL SCREENING AND EARLY TREATMENT}

4.1. Neurodevelopmental outcomes

4.2. Development of goiter in thyroid dyshormonogenesis

4.3. Growth, puberty, and fertility

4.4. Bone, metabolic, and cardiovascular health

4.5. Patient and professional education, and healthrelated quality of life

4.6. Transition to adult care

\subsection{Neurodevelopmental outcomes}

\section{Summary}

- Psychomotor development and school progression should be periodically evaluated in all children with $\mathrm{CH}$; speech delay, attention and memory problems, and behavioral problems are reasons for additional evaluation $(1 /++0)$.

- In the small proportion of children with $\mathrm{CH}$ who do display significant psychomotor developmental delay and syndromic $\mathrm{CH}$ with brain abnormalities, it is crucial to rule out other causes of intellectual impairment than $\mathrm{CH}(1 /+00)$.

- Not just neonatal but also repeated hearing tests should be carried out before school age and, if required, during further follow-up $(2 /++0)$.

Evidence. In the vast majority of early and adequately treated children with $\mathrm{CH}$, neurodevelopmental and school outcomes level are normal $(90,91,159-161)$, and intellectual disability-defined as an IQ $<70$ - has virtually disappeared (162). In the past, patients with severe $\mathrm{CH}$ treated with a low initial LT4 dose had lower IQ scores (although within normal range), and subtle neurological deficits in cognitive and motor development $(163,164)$ when compared with control populations, including healthy siblings $(164,165)$. In the past two decades, early treatment with a high initial LT4 ( $\geq 10 \mu \mathrm{g} / \mathrm{kg}$ per day) and improvement in the management of $\mathrm{CH}$ patients has resulted in better cognitive and motor developmental outcomes, comparable with those of sibling controls $(90,91)$.

However, despite early and adequate treatment, patients with severe $\mathrm{CH}$ may still have subtle cognitive and motor deficits, and lower educational attainment (161,166-168). These deficits may reflect prenatal brain damage due to $\mathrm{TH}$ insufficiency in utero, not completely reverted by postnatal treatment. Even though transplacental supply of maternal T4 may protect the fetal brain from severe neurological impairment, it may not be sufficient to protect from severe fetal hypothyroidism (168). Children with $\mathrm{CH}$ may also display reduced hippocampal volume (169) and abnormal cortical morphology among brain regions (thinning or thickening) (170), which may explain subtle and specific deficits in memory, language, sensorimotor, and visuospatial function $(169,170)$. In addition, early episodes of both under- and overtreatment may be associated with permanent behavioral problems in a limited number of preadolescent children with $\mathrm{CH}$ (109). Overtreatment during the first months of life (with the exception of fT4 above the normal range with not supressed TSH and/or without signs or symptoms of hyperthyroidism), a critical period for brain development, may be associated with attention deficit at the school age $(109,171,172)$, and lower IQ scores $(108,173,174)$. Finally, other factors such as socioeducational status (71) and poor adherence to the treatment $(71,167,174)$ may also negatively affect cognitive outcome and educational attainement. Therefore, psychomotor development and school progression should be periodically evaluated in all children with $\mathrm{CH}$. In case of doubt, evaluation by a specialized team is indicated at specific ages $(12,18,24$, and 36 months, 5, 8, and 14 years) to monitor progression of specific developmental skills (58). Speech delay, attention and memory problems, and behavioral problems are reasons for additional evaluation. In the small proportion of children with $\mathrm{CH}$ who do display significant delay in psychomotor development, it is necessary to rule out other causes of intellectual impairment than $\mathrm{CH}$. Undiagnosed hearing impairment can adversely impair speech development, school performance, and quality of life $(71,72,175)$. TH plays a role in cochlear and auditory function development $(71,176,177)$. Despite early and adequate LT4 treatment, mild and subclinical hearing impairment has been reported in $\sim 20 \%$ to $25 \%$ of adolescents with $\mathrm{CH}$. The risk of hearing loss was higher than in healthy controls (3\%), and closely associated with the severity of $\mathrm{CH}(72,178)$. Young adults with $\mathrm{CH}$ reported hearing impairment more frequently $(9.5 \%)$ than the general population (2.5\%) (71). Hearing loss was mostly bilateral, mild to moderate, of the sensorineural type, concerned high or very high frequencies, and in some cases required hearing aids. Even after exclusion of patients with Pendred syndrome, the risk of developing a hearing impairment seems to be more than three times higher in $\mathrm{CH}$ subjects than in the general population (72). Not just neonatal, but also repeated hearing tests should be carried out before school age and, if required, during follow-up. 


\subsection{Development of goiter in thyroid dyshormonogenesis}

\section{Summary}

- Children and adolescents with primary $\mathrm{CH}$ due to dyshomonogenesis may develop goiter and nodules; in these cases, serum TSH should be carefully targeted in the lower part of normal range, and periodical ultrasound investigation is recommended to monitor thyroid volume $(2 /++0)$.

- Since a few cases of thyroid cancer have been reported, fine needle aspiration biopsy for cytology should be performed in case of suspicious nodules on ultrasound investigation $(1 /+00)$.

Evidence. Children and adolescents with primary $\mathrm{CH}$ due to dyshormonogenesis (mainly TPO gene, but also SLC5A5/NIS, SLC26A4/PDS, DUOX, and TG gene mutations) may have an increased risk of developing goiter and thyroid nodules, and may even have an increased risk of malignancy. However, to date only a few cases of thyroid cancer (either papillary or follicular) have been reported in patients with long-standing $\mathrm{CH}$. In some cases, goiter was already present and thyroid nodules (isolated or multiple) developed despite apparently adequate LT4 treatment. In other cases, poor compliance to treatment, with persistently high TSH levels during adolescence, was the probable cause (179-182). Therefore, TSH should be targeted in the lower part of normal range during treatment of dyshormogenic $\mathrm{CH}$. Despite the rare occurrence of thyroid carcinoma in $\mathrm{CH}$ patients, we recommend periodical neck US-for example, every 2 to 3 years-in children and adolescents with goitrous $\mathrm{CH}$ due to dyshormonogenesis (including NIS gene mutations), to identify nodules that may require fine needle aspiration biopsy to rule out thyroid carcinoma.

\subsection{Growth, puberty, and fertility}

\section{Summary}

- Adequately treated children with nonsyndromic $\mathrm{CH}$ have normal growth and puberty, and their fertility does not differ from individuals who do not have $\mathrm{CH}$ (1/ $+++)$.

Evidence. Early and adequately treated children with nonsyndromic $\mathrm{CH}$ have normal growth and pubertal development (183-187). Adult height is normal and comparable with siblings, with no effects of severity of $\mathrm{CH}$ at diagnosis, CH etiology, or LT4 starting dose (47,183-185); moreover, in the majority of children, adult height is above the target height in both sexes $(47,183,184)$. Onset of puberty occurs at the normal age in the vast majority of $\mathrm{CH}$ patients and progresses normally in both sexes $(47,183,114)$. The same applies to age at menarche and menstrual cycles $(114,183)$. In adults, fertility is generally normal (188). However, women with $\mathrm{CH}$ may have an increased risk of adverse pregnancy outcomes. In addition, their offspring is at risk for poorer motor coordination (see also Section 3.5) $(154,156)$.

\subsection{Bone, metabolic, and cardiovascular health}

\section{Summary}

- Adequately treated children with nonsyndromic $\mathrm{CH}$ also have normal bone, metabolic, and cardiovascular health $(1 /++0)$.

Evidence. Thyroid hormones play an important role in skeletal growth and bone mineral homeostasis. At birth, skeletal maturation is delayed in the majority of $\mathrm{CH}$ patients with severe hypothyroidism (70); however, within the first months of life, LT4 treatment rapidly normalizes bone maturation (71). Since thyroid hormones have major effects on bone remodeling, LT4 overtreatment may increase bone turnover with higher bone resorption than formation, resulting in progressive bone loss (189). Yet, long-term studies in children and young adults with $\mathrm{CH}$ have shown normal bone mineral density (190-193), suggesting that early started and adequate LT4 treatment is not harmful to bone health. Given the importance of sufficient calcium intake, patients with $\mathrm{CH}$, in addition to adequate LT4 treatment, should consume 800 to $1200 \mathrm{mg}$ calcium daily; if dietary calcium intake is low, supplements should be added $(1,190)$.

Body mass index and composition are generally normal in children and adult with $\mathrm{CH}(90,91,187)$, and comparable with that of the general population. However, earlier adiposity rebound (194-196) and increased risks of being overweight or obese have been reported in up to $37 \%$ of young adults with $\mathrm{CH}(47,71,114)$. Therefore, lifestyle interventions, including diet and physical exercise, should be encouraged to avoid metabolic abnormalities (1).

In addition to an increased risk of congenital heart disease (86-88), neonates with untreated $\mathrm{CH}$ may have increased aortic intimal-media thickness (IMT), serum cholesterol levels (197), and impaired cardiac function $(198,199)$ reversed by early LT4 treatment (200).

Young adults with $\mathrm{CH}$ have normal blood pressure, glucose, and lipid metabolism, and carotid IMT $(90,200)$. However, repeated episodes of inadequate treatment may place them at risk of subtle cardiovascular dysfunction such as low exercise capacity, impaired diastolic function, increased IMT, and mild endothelial dysfunction (201). Whether these subtle abnormalities result in impaired quality of life or in an increased risk of cardiovascular disease needs to be further clarified. Anyway, good adherence to treatment in adolescents and young adults with $\mathrm{CH}$ is mandatory for optimal metabolic and cardiovascular health.

\subsection{Patient and professional education, adherence, and health-related quality of life}

\section{Summary}

- Medical education about $\mathrm{CH}$ should be improved at all levels, with regular updates $(1 /+++)$.

- Education of parents, starting at the time of the diagnosis, and later on of the patient, is essential not only throughout childhood, but also during transition to adult care and in women during pregnancy $(1 /+++)$.

- Since adherence to treatment may influence the outcomes, it should be promoted throughout life $(1 /++0)$. 
Evidence. It is very clear, and it should not have to be stated here, that medical professionals should have basic knowledge about $\mathrm{CH}$. The education of parents, starting at diagnosis and updated regularly, and of $\mathrm{CH}$ patients throughout childhood is mandatory. Good understanding of $\mathrm{CH}$ is essential to manage parental anxiety attitude, and to promote treatment adherence throughout life. Both are important conditions to assure optimal outcomes in $\mathrm{CH}$. Adequate education of patients is also important to improve self-esteem and health-related quality of life (HRQoL), and to assure treatment adherence particularly during adolescence and pregnancy. The perception of the impact of $\mathrm{CH}$ on behavior varies with age and differs between children and their parents (202). Most (71,203,204), but not all $(202,205)$, studies suggest that children and young adults with $\mathrm{CH}$ have an increased risk for lower HRQoL. Young adults with $\mathrm{CH}$ do not report problems concerning autonomy and sexual functioning. However, compared with the general population, they experience lower HRQoL with respect to cognitive and social functioning, daily activities, aggressiveness, and selfworth (204), which was already present in childhood (203). Moreover, young adults with $\mathrm{CH}$ are more likely to report associated chronic diseases, hearing impairment, visual problems, and overweight than their peers. Fewer attain the highest socioeconomic category and full-time employment, and more are still living with their parents. $\mathrm{CH}$ severity at diagnosis, long-term treatment adequacy, and the presence of other chronic health conditions seem to be the main determinants of educational achievement and HRQoL scores. Yet, despite these subtle disadvantages, most patients well integrated into society (71).

\subsection{Transition to adult care}

\section{Summary}

- When patients are transferred from pediatric to adult care, the main aims are continuity of care and, with that, optimal clinical outcomes and quality of life, and to increase understanding of $\mathrm{CH}$ and promote selfmanagement $(1 /+++)$.

Evidence. The period of transition from pediatric to adult care can be challenging since it is associated with an increased risk of poor treatment compliance and inadequate follow-up that may have repercussions, in terms of increased morbidity, and poor educational and social outcomes $(206,207)$. Family structure and parental involvement are important for preventing and tackling this problem. Finally, given the female preponderance in all thyroid diseases and the finding that (subclinical) hypothyroidism may be associated with subfertility and adverse pregnancy and offspring outcomes, improvement and maintenance of disease control in young women are crucial $(154,156)$.

\section{GENETICS OF CH, GENETIC COUNSELING, AND ANTENATAL MANAGEMENT}

5.1. Criteria for genetic counseling

5.2. Genetics of $\mathrm{CH}$

5.3. Antenatal diagnostics, evaluation of fetal thyroid function, and management of fetal hypothyroidism

\subsection{Criteria for genetic counseling}

\section{Summary}

- Genetic counseling should be targeted rather than general (to all $\mathrm{CH}$ patients), and done by an experienced professional $(2 /++0)$.

- Counseling should include explaining inheritance and the risk of recurrence of the patient's primary or central form of $\mathrm{CH}$, based on the $\mathrm{CH}$ subtype, the family history, and, if known, the (genetic) cause $(1 /++0)$.

- Parents with a child, or families with a member with $\mathrm{CH}$, should have access to information about the two major forms of primary $\mathrm{CH}-\mathrm{TD}$ and dyshormonogenesisand, if included in the neonatal screening, about central $\mathrm{CH}(1 /+++)$.

Evidence. Genetic counseling is highly recommended for patients and families with one or more affected member(s) with $\mathrm{CH}$. Precise criteria were already established for the $\mathrm{CH}$ consensus guideline published in 2014 (1). Table 1 describes proposed criteria for genetic counseling.

Table 1. Situations in Which Genetic Counseling ShOUld Be Proposed

\section{Pregnant women \\ Positive family history for nonsyndromic $\mathrm{CH}$}

Dyshormonogenesis (previously affected child) $(1 /+++)$

Dysgenesis (at least one member of the family) $(2 /++0)$

Positive family history of syndromic $\mathrm{CH}$ with:

Neurological disorders, including unexplained intellectual impairment

Deafness

Congenital heart disease, surfactant deficiency syndrome

Cleft palate

Kidney malformations

Any sign of Albright hereditary osteodystrophy (GNAS mutation) $(1 /++0)$

Unexplained abnormality of T4, T3, or TSH levels in family members (mild forms of $\mathrm{CH})(2 /++0)$

II. Infant or child with $\mathrm{CH}(2 /++0)$

Subject with

Deafness

Neurological signs (hypotonia, choreoathetosis, intellectual disability)

Lung disorders (surfactant deficiency syndrome, interstitial lung disease)

Congenital heart disease

Cleft palate

Kidney malformations

Any sign of Albright hereditary osteodystrophy (GNAS mutation)

Family history

Consanguinity

Kidney malformations

Deafness

Specific malformations (as already listed)

Unexplained intellectual impairment despite adequate treatment of $\mathrm{CH}$ in family members

Any sign of Albright hereditary osteodystrophy (GNAS mutation)

$\mathrm{CH}$, congenital hypothyroidism; $\mathrm{T} 3$, triiodothyronine; $\mathrm{T} 4$, thyroxine; $\mathrm{TSH}$, thyrotropin. 
Detailed phenotypic description of the index patient's $\mathrm{CH}$ form is essential and should include the presence or absence of associated malformations (syndromic vs. isolated $\mathrm{CH}$ ), guiding genetic counseling and, if possible and necessary, genetic testing. Patients and family members should be informed about the inheritance and the risk of recurrence, and the presence of associated disorders in case of syndromic $\mathrm{CH}$.

Accurate genotyping/genetic testing of patients with $\mathrm{CH}$ by mutation analysis of candidate genes can or may (i) explain the disease; (ii) predict the risk of $\mathrm{CH}$ and extrathyroidal defects in family members (to be performed in all cases of syndromic primary $\mathrm{CH}$, and in central $\mathrm{CH}$ ); (iii) identify carriers of $N K X 2-1$ gene mutations who are at risk of lifethreatening respiratory disease (208); (iv) enable "personalized" LT4 treatment to prevent goiter formation, which may occur in $\mathrm{CH}$ due to $T P O$ or $T G$ gene mutations if $\mathrm{TSH}$ concentrations are not carefully kept in the lower part of the reference interval; and (v) identify patients with mild TSH resistance in whom long-term LT4 treatment may be nonbeneficial (50).

\subsection{Genetics of $\mathrm{CH}$}

\section{Summary}

- If genetic testing is performed, its aim should be improving diagnosis, treatment, or prognosis $(1 /++0)$.

- Before doing so, possibilities and limits of genetic testing should be discussed with parents or families $(1 /++0)$.

- When available, genetic testing should be performed by means of new techniques, such as CGH array, NGS of gene panels (targeted NGS), or WES $(1 /++0)$.

- Preferably, genetic testing or studies should be preceded by careful phenotypic description of the patient's $\mathrm{CH}$, including morphology of the thyroid gland $(2 /++0)$.

- Not only thyroid dyshormonogenesis, but also familial occurrence of dysgenesis and central hypothyroidism should lead to further genetic testing $(1 /++0)$.

- Any syndromic association should be studied genetically, not only to improve genetic counseling, but also to identify new candidate genes explaining the association $(1 /++0)$.

- Further research is needed to better define patients or patient groups that will benefit most from these new diagnostic possibilities $(2 /++0)$.

\section{Evidence}

Primary $\mathrm{CH}$. TD due to thyroid maldevelopment is the most frequent cause of permanent primary $\mathrm{CH}$, explaining $\sim 65 \%$ of cases $(12,209)$. In contrast to TD with conditions such as athyreosis or thyroid ectopy, the other $35 \%$ is best described as GIS of which $<50 \%$ is due to inherited defects of $\mathrm{TH}$ synthesis (dyshormonogenesis). TD is considered a sporadic disease. However, the familial component cannot be ignored, suggesting a genetic predisposition and a probably complex inheritance mode $(210,211)$. In only $5 \%$ of TD cases, a genetic cause is identified with mutations in TSHR (212), or in genes encoding transcription factors involved in thyroid development (TTF1/NKX2.1, PAX8, FOXE1, NKX2-5, and
GLIS3) (213,214). During the past years, novel and faster genetic and molecular tests, and the availability of large wellphenotyped cohorts of patients have led to the discovery of new genetic causes of $\mathrm{CH}$. Heterozygous mutations in the $J A G 1$ gene, responsible for Alagille syndrome and encoding the jagged protein in the Notch pathway, have been identified in TD patients (mainly with orthotopic thyroid hypoplasia) (77,215). By WES in familial TD cases, Carré et al. found borealin (encoded by BOREALIN), a major component of chromosomal passenger complex, to be also involved in thyrocyte migration and adhesion, explaining cases of thyroid ectopy (216). Mutations or deletion in the NTN1 gene have been found in patients with TD. Netrin is part of a family of laminin-related proteins, involved in cell migration and possibly in the development of pharyngeal vessels (217). Finally, mutations in the TUBB1 (tubulin, beta 1 class VI) gene have recently been identified in patients from three families with TD (mostly ectopy) and abnormal platelet physiology (basal activation and exaggerated platelet aggregation) (218). Functional studies in knockout mice validated the role of Tubb1 in thyroid development, function, and disease.

With respect to the cause of the mild nonautoimmune subclinical hypothyroidism in neonates and infants with Down's syndrome, new insights were provided by a study in Dyrk1A (+/++) mice, showing abnormal thyroid development and function (42). How overexpression of this gene causes thyroid abnormalities remains to be elucidated. Another more frequent form of syndromic $\mathrm{CH}$ is BLT syndrome due to $N K X 2-1$ haploinsufficiency. Extensive genetic analysis of a large group of affected patients revealed novel variants, expanding BLT syndrome phenotype (219). Table 2 summarizes genes associated with TD.

In contrast to $\mathrm{TD}$, thyroid dyshormonogenesis is inherited in an autosomal recessive pattern and, except for Pendred syndrome, $\mathrm{CH}$ is isolated in most cases. Genes involved in TH synthesis are SLC5A5 (NIS), SLC26A4 (PDS), TPO, TG, $D U O X 2, D U O X A 2$, and IYD (DEHAL1). These seven genes encode proteins for the various steps in this process. The use of modern genetic techniques, such as single nucleotide polymorphisms arrays and NGS (WES/whole genome sequencing), has provided new insights into the genetics of $\mathrm{CH}$. First, NGS has identified new genes and/or extended the assumed thyroid phenotype, resulting from mutations in genes responsible for $\mathrm{TH}$ synthesis, causing dyshormonogenesis. For instance, biallelic mutations in SLC26A7 cause goitrous $\mathrm{CH}(220,221)$. SLC26A7 is a member of the same transporter family as SLC26A4 (pendrin), an anion exchanger with affinity for iodide and chloride (among others). However, in contrast to pendrin, SLC26A7 does not mediate cellular iodide efflux and affected individuals have normal hearing (220,221). Mutations in SLC26A4/PDS (222), TPO (222a) and DUOX2 (223) have been unexpectedly found in patients with nongoitrous $\mathrm{CH}$ and thyroid hypoplasia, narrowing the gap between TD and dyshormonogenesis. Recently, DUOX2 mutations have also been reported in patients with thyroid ectopy; however, further studies are needed to confirm and explain this striking finding (224). Moreover, the first $\mathrm{CH}$ patients with both $D U O X 1$ and DUOX2 mutations have been reported, suggesting that $\mathrm{CH}$ can have a digenic cause (225). DUOX2 mutations have also been found in patients with early-onset inflammatory bowel disease, suggesting an extrathyroidal role for DUOX2 $(226,227)$. Table 3 gives genes 
Table 2. Genes Associated with Thyroid Dysgenesis or Syndromic Primary Congenital Hypothyroidism

\begin{tabular}{|c|c|c|c|c|}
\hline Gene (OMIM) & Protein role & $\begin{array}{l}\text { Typical thyroid } \\
\text { phenotype }\end{array}$ & $\begin{array}{l}\text { Mode of } \\
\text { inheritance }\end{array}$ & Associated conditions \\
\hline NKX2-1 (600635) & $\mathrm{NF}$ & Variable & $\mathrm{AD}$ & $\begin{array}{l}\text { Respiratory distress, } \\
\text { choreoathetosis, variable } \\
\text { expressivity }\end{array}$ \\
\hline FOXE1 (602617) & $\mathrm{NF}$ & $\begin{array}{l}\text { Athyreosis, severe } \\
\text { hypoplasia }\end{array}$ & AR & $\begin{array}{l}\text { Cleft palate, choanal atresia, } \\
\text { and spiky hair }\end{array}$ \\
\hline PAX8 (167415) & $\mathrm{NF}$ & Variable & $\mathrm{AD}$ & $\begin{array}{l}\text { Urogenital tract defects } \\
\text { (horseshoe kidney, renal } \\
\text { agenesis, ureter, and testes } \\
\text { anomalies), variable } \\
\text { expressivity }\end{array}$ \\
\hline NKX2-5 (600584) & $\mathrm{NF}$ & $\begin{array}{l}\text { Thyroid in situ, variable } \\
\text { hypothyroidism }\end{array}$ & Unclear & Congenital heart malformations \\
\hline GLIS3 (610192) & NF & Variable & AR & $\begin{array}{l}\text { Neonatal diabetes, polycystic } \\
\text { kidneys, and cholestasis }\end{array}$ \\
\hline$J A G 1(601920)$ & $\begin{array}{l}\text { Jagged 1: Notch receptor } \\
\text { ligand }\end{array}$ & $\begin{array}{l}\text { Variable orthotopic } \\
\text { hypoplasia }\end{array}$ & $\mathrm{AD}$ & $\begin{array}{l}\text { Heart malformations, variable } \\
\text { expressivity }\end{array}$ \\
\hline$T B X 1(602054)$ & $\mathrm{NF}$ & Thyroid in situ & $\mathrm{AD}$ & $\begin{array}{l}\text { Di George syndrome with } \\
\text { congenital heart } \\
\text { malformations, variable } \\
\text { expressivity }\end{array}$ \\
\hline NTN1 (601614) & $\begin{array}{l}\text { Laminin-related secreted } \\
\text { protein }\end{array}$ & Thyroid ectopy & unknown & Arthrogryposis \\
\hline CDCA8 (609977) & $\begin{array}{l}\text { Cell division cycle } \\
\text { associated protein } 8 \text { or } \\
\text { Borealin: component of } \\
\text { the chromosomal } \\
\text { passenger complex }\end{array}$ & $\begin{array}{l}\text { Thyroid ectopy, } \\
\text { hemiagenesis, } \\
\text { thyroid asymmetry }\end{array}$ & $\begin{array}{l}\text { Variable } \\
\qquad(\mathrm{AD}, \mathrm{AR})\end{array}$ & None in sporadic cases \\
\hline TUBB1 (612901) & $\begin{array}{l}\text { Member of the } \beta \text {-tubulin } \\
\text { protein family }\end{array}$ & Thyroid dysgenesis & $\mathrm{AD}$ & $\begin{array}{l}\text { Formation of macroplatelets } \\
\text { and hyperaggregation of } \\
\text { platelets }\end{array}$ \\
\hline
\end{tabular}

AD, autosomal dominant; AR, autosomal recessive; NF, nuclear factor; OMIM, Online Mendelian Inheritance in Men (https://www.ncbi .nlm.nih.gov/omim/).

implicated in thyroid dyshormonogenesis. Also, recently, NGS studies in cohorts of $\mathrm{CH}$ patients screened for mutations in sets of $\mathrm{CH}$ genes revealed that a significant proportion of these patients has multiple variations in more than one thyroid-specific gene $(89,228,229)$. Strikingly, these variations were found in genes encoding both thyroid transcription factors and proteins involved in $\mathrm{TH}$ synthesis, independently of the thyroid phenotype. These variations in more than one gene (oligogenicity) should, therefore, be considered as a plausible hypothesis for the genetic aetiology of $\mathrm{CH}$ (89). These novel data may also provide an explanation for the sporadic presentation of $\mathrm{CH}$ and observed complex modes of inheritance. In such context, JAG1 may act as a gene modifier in a multifactorial architecture of $\mathrm{CH}(215)$.

Central $\mathrm{CH}$. Thanks to NGS, the number of probable genetic causes of isolated central $\mathrm{CH}$ and central $\mathrm{CH}$ within the framework of MPHD has increased (Table 4). Isolated central $\mathrm{CH}$ due to biallelic $T S H \beta$ gene mutations is associated with severe hypothyroidism and characterized by the typical manifestations of $\mathrm{CH}$ (hypotonia, jaundice, umbilical hernia, macroglossia, etc.). If left untreated, these patients develop cretinism comparable with patients with severe primary $\mathrm{CH}$ (230-232). Therefore, central $\mathrm{CH}$ must be ruled out in all infants with signs or symptoms of $\mathrm{CH}$ and a low, normal, or only slightly elevated TSH concentration.
To date, defective thyrotropin-releasing hormone (TRH) action due to biallelic mutations in the TRHR gene has been described in only a few families (45). Although prolonged neonatal jaundice was reported in one female, even complete TRH resistance does not cause severe neonatal hypothyroidism. The diagnosis in three of the four probands with biallelic TRHR mutations was made during childhood because of delayed growth accompanied by lethargy and fatigue or by overweight. However, complete TRH resistance diagnosed by genetic testing has been diagnosed in a pregnant woman (233). Immunoglobulin superfamily member 1 gene (IGSF1) mutations are the molecular cause of a recently described X-linked syndrome, including mild-to-moderate central $\mathrm{CH}$. In this syndrome, central $\mathrm{CH}$ is associated with abnormal testicular growth leading to adult macro-orchidism (+2.0 standard deviation score), a tendency toward pubertal delay, low prolactin, and, rarely, reversible growth hormone deficiency $(234,235)$. Some female carriers can also manifest central $\mathrm{CH}$. Recent data indicate IGSF1 as the most frequently implicated gene in congenital central $\mathrm{CH}$ (235).

Mutations in the TBL1X gene are the second most frequent cause of X-linked central $\mathrm{CH}$. TBL1X, transducin-like protein 1 , is an essential subunit of the nuclear receptor corepressorsilencing mediator for retinoid and $\mathrm{TH}$ receptor complex, the major $\mathrm{TH}$ receptor $\mathrm{CoR}$ involved in T3-regulated gene expression. In addition to central $\mathrm{CH}$, many patients exhibit 
Table 3. Genes Associated with Thyroid Dyshormonogenesis

\begin{tabular}{|c|c|c|c|c|}
\hline Gene (OMIM) & Protein role & Typical thyroid phenotype & $\begin{array}{l}\text { Mode of } \\
\text { inheritance }\end{array}$ & Associated conditions \\
\hline TSHR (603372) & $\begin{array}{l}\text { G-protein coupled } \\
\text { receptor }\end{array}$ & $\begin{array}{l}\text { Complete or partial TSH } \\
\text { resistance: apparent } \\
\text { athyreosis } \rightarrow \text { thyroid in } \\
\text { situ and severe } \rightarrow \text { mild } \\
\text { hypothyroidism }\end{array}$ & $\mathrm{AD}, \mathrm{AR}$ & \\
\hline GNAS (139320) & $\begin{array}{l}\text { Alpha subunit of the } \\
\text { stimulatory guanine } \\
\text { nucleotide-binding } \\
\text { protein (G protein) }\end{array}$ & $\begin{array}{l}\text { Partial TSH resistance, mild } \\
\text { hypothyroidism }\end{array}$ & $\begin{array}{l}\text { Maternal } \\
\text { inheritance, } \\
\text { parental } \\
\text { imprinting of } \\
\text { gene locus }\end{array}$ & $\begin{array}{l}\text { PseudoHypo } \\
\text { Parathyroidism } \\
\text { (multiple hormone } \\
\text { resistances) }\end{array}$ \\
\hline SLC5A5 (601843) & $\begin{array}{l}\text { Sodium iodide } \\
\text { symporter }\end{array}$ & $\begin{array}{l}\text { Absent or low iodide uptake } \\
\text { at scintiscan, variable } \\
\text { hypothyroidism, and goiter }\end{array}$ & $\mathrm{AR}$ & \\
\hline $\begin{array}{l}S L C 26 A 4 / P D S \\
\quad(605646)\end{array}$ & $\begin{array}{l}\text { Pendrin: anion } \\
\text { transporter }\end{array}$ & $\begin{array}{l}\text { Partial iodide organification } \\
\text { defect, mild-to-moderate } \\
\text { hypothyroidism, goiter, } \\
\text { high serum Tg }\end{array}$ & AR & $\begin{array}{l}\text { Pendred syndrome: } \\
\text { sensorineural deafness } \\
\text { with enlarged vestibular } \\
\text { aqueduct, predisposition } \\
\text { to alkalosis }\end{array}$ \\
\hline $\begin{array}{l}\text { DUOX1/DUOX2 } \\
\quad(606758 / 606759)\end{array}$ & $\begin{array}{l}\text { Dual oxydases: } \\
\text { peroxide generating } \\
\text { system }\end{array}$ & $\begin{array}{l}\text { Partial or complete iodide } \\
\text { organification defect, goiter, } \\
\text { transient or permanent } \\
\text { hypothyroidism of variable } \\
\text { severity, high serum } \mathrm{Tg}\end{array}$ & $\mathrm{AD}, \mathrm{AR}$ & \\
\hline DUOXA2 (612772) & $\begin{array}{l}\text { Dual oxydase } \\
\text { associated protein: } \\
\text { a endoplasmic } \\
\text { reticulum } \\
\text { chaperone protein }\end{array}$ & $\begin{array}{l}\text { Partial or complete iodide } \\
\text { organification defect, goiter, } \\
\text { transient or permanent } \\
\text { hypothyroidism of variable } \\
\text { severity, high serum } \mathrm{Tg}\end{array}$ & AR & \\
\hline TPO (606765) & $\begin{array}{l}\text { Thyroid peroxidase: } \\
\text { iodide } \\
\text { organification and } \\
\text { thyronine coupling }\end{array}$ & $\begin{array}{l}\text { Complete iodide } \\
\text { organification defect, } \\
\text { severe hypothyroidism, } \\
\text { goiter, high serum } \mathrm{Tg}\end{array}$ & AR & \\
\hline$T G(188450)$ & $\begin{array}{l}\text { Tg: glycoprotein } \\
\text { precursor to the } \\
\text { thyroid hormones }\end{array}$ & $\begin{array}{l}\text { High iodide uptake, variable } \\
\text { hypothyroidism, congenital } \\
\text { or rapidly growing goiter, } \\
\text { low serum Tg }\end{array}$ & AR & \\
\hline $\begin{array}{c}I Y D / D E H A L \\
(612025)\end{array}$ & $\begin{array}{l}\text { Dehalogenase } \\
\text { providing iodide } \\
\text { salvage in thyroid }\end{array}$ & $\begin{array}{l}\text { Conserved iodide uptake, } \\
\text { negative perchlorate } \\
\text { discharge test, goiter, } \\
\text { variable hypothyroidism, } \\
\text { high serum Tg and } \\
\text { MIT/DIT concentrations in } \\
\text { serum and urine }\end{array}$ & $\begin{array}{l}\mathrm{AR} \text { or } \mathrm{AD} \text { with } \\
\text { incomplete } \\
\text { penetrance }\end{array}$ & \\
\hline SLC26A7 (608479) & Anion transporter & $\begin{array}{l}\text { Goiter, variable } \\
\text { hypothyroidism, conserved } \\
\text { iodide uptake, partial } \\
\text { defect at perchlorate } \\
\text { discharge, high serum } \mathrm{Tg}\end{array}$ & AR & \\
\hline
\end{tabular}

$\mathrm{AD}$, autosomal dominant; AR, autosomal recessive; MIT/DIT, monoiodotyrosine/diiodotyrosine; Tg, thyroglobulin.

hearing loss (236). Finally, mutations in IRS4 are another cause of X-linked mild central CH. Since IRS4 is involved in leptin signaling, the cause of the central $\mathrm{CH}$ may be disrupted leptin signaling (237). Central $\mathrm{CH}$ is more frequently part of MPHD and can be associated with one or more other pituitary hormone deficiences. In addition, a certain percentage of affected patients has morphological abnormalities of the pituitary gland or hypothalamus, or other neurological defects $(25,45)$. Table 4 presents genes implicated in central hypothyroidism.

\subsection{Antenatal diagnostics, evaluation of fetal thyroid function, and management of fetal hypothyroidism}

\section{Summary}

- We recommend antenatal diagnosis in cases of goiter fortuitously discovered during systematic ultrasound examination of the fetus, in relation to thyroid dyshormonogenesis $(1 /+++)$; a familial recurrence of $\mathrm{CH}$ due to dyshormonogenesis (25\% recurrence rate) (1/ 


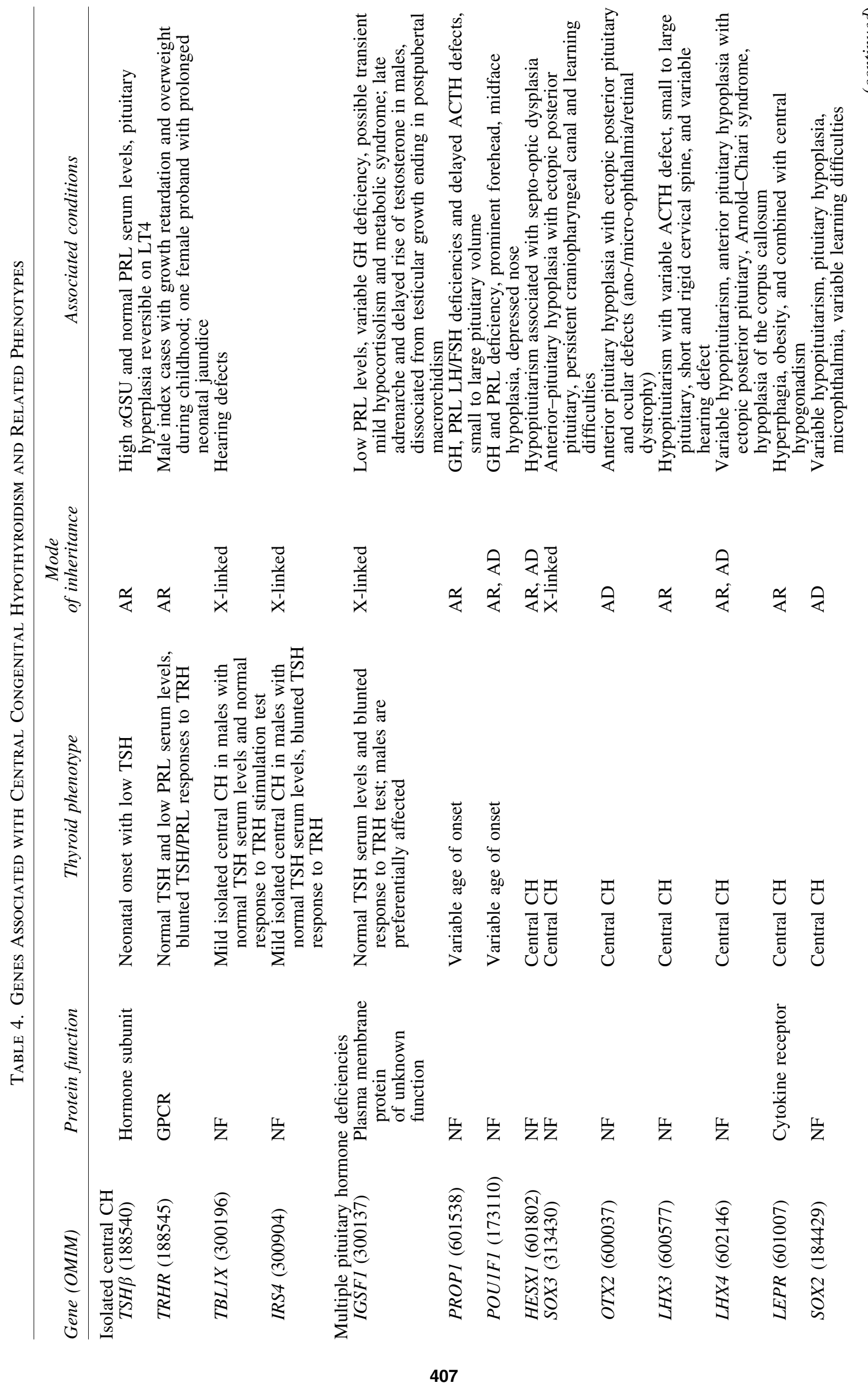




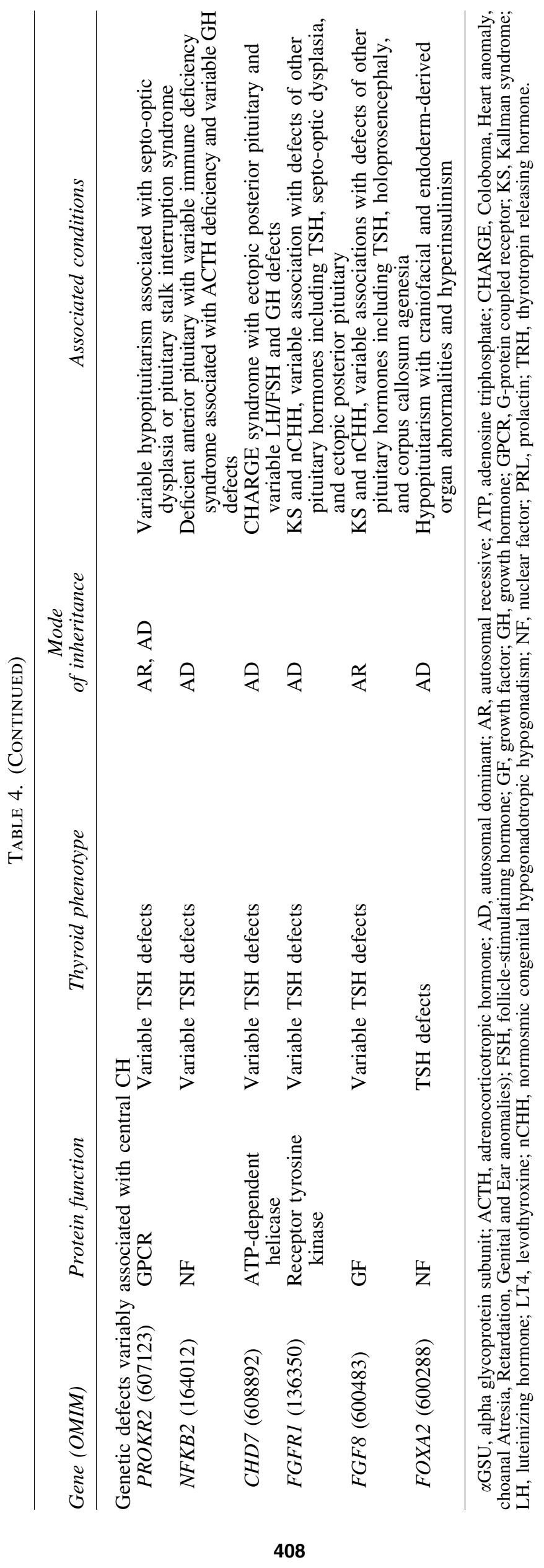


+++ ); and known defects of genes involved in thyroid function or development with potential germline transmission $(1 /++0)$. Special issues should be considered for syndromic cases with potential mortality and possible germline mosaicism (as for $N K X 2-1$ gene mutation/ deletion and severe pulmonary dysfunction with possible transmission through germline mosaicism). In such circumstances, the discussion of the prenatal diagnosis should be open. The therapeutic management of affected fetuses should comply with the laws in force in the country concerned $(1 /++0)$. The familial recurrence of $\mathrm{CH}$ due to dysgenesis ( $2 \%$ of familial occurrences) requires further study to determine the feasibility and clinical relevance for antenatal detection.

- For the evaluation of fetal thyroid volume, we recommend ultrasound scans at 20 to 22 weeks gestation to detect fetal thyroid hypertrophy and potential thyroid dysfunction in the fetus. Goiter or an absence of thyroid tissue can also be documented by this technique. Measurements should be made as a function of GA, and thyroid perimeter and diameter should be measured to document goiter $(1 /+++)$.

- If a (large) fetal goiter is diagnosed, prenatal care should be provided in a specialized center of prenatal care $(1 /+++)$.

- We recommend cordocentesis, rather than amniocentesis, as the reference method for assessing fetal thyroid function. Norms have been established as a function of GA. This examination should be carried out only if prenatal intervention is considered $(1 /+++)$.

- In most cases, fetal thyroid function can be inferred from context and ultrasound criteria, and fetal blood sampling is, therefore, only exceptionally required $(2 /++0)$.

- We strongly recommend fetal treatment by intraamniotic LT4 injections in a euthyroid pregnant woman with a large fetal goiter associated with hydramnios and/or tracheal occlusion; in a hypothyroid pregnant woman, we recommend to treat the woman (rather the fetus) with LT4 $(1 /++0)$.

- For goitrous nonimmune fetal hypothyroidism leading to hydramnios, we recommend intra-amniotic injections of LT4 to decrease the size of the fetal thyroid gland. The injections should be performed by multidisciplinary specialist teams $(1 /+++)$.

- The expert panel proposes the use of $10 \mu \mathrm{g} / \mathrm{kg}$ estimated fetal weight per 15 days in the form of intraamniotic injections. The risks to the fetus and the psychological burden on the parents should be factored into the risk-benefit evaluation $(2 /+00)$.

Evidence. Antenatal diagnostics is advised in case of fortuitously discovered fetal goiter during fetal US examination in an anti-TSHR antibodies negative mother, an earlier child with primary $\mathrm{CH}$ due to dyshormonogenesis (and a $25 \%$ risk of recurrence), and in an earlier child with (severe) syndromic $\mathrm{CH}$. How to evaluate fetal thyroid function and to manage (nonautoimmune) fetal hypothyroidism have been described in the $2014 \mathrm{CH}$ concensus guidelines (1). In short, fetal thyroid size can be assessed by US at 20 to 22 weeks, and at 32 weeks gestation. When thyroid measurement values based on diameter or perimeter are above the 95 th percentile
(238), the mother and fetus should be referred to a specialized center for prenatal care. If prenatal intervention is considered, cordocentesis can be performed to assess fetal thyroid function. Conditions that may be a reason for fetal treatment are a large fetal goiter with progressive hydramnios, and risk of premature delivery or concerns about tracheal occlusion. If fetal treatment is considered in a euthyroid pregnant woman, one way is to administer intra-amniotic LT4 injections in a dosage of $10 \mu \mathrm{g} / \mathrm{kg}$ estimated fetal weight per 15 days. Studies have confirmed the feasibility and safety of intraamniotic LT4 injection and strongly suggest that this treatment is effective for decreasing goiter size. However, none of the many LT4 regimens used ensures euthyroidism at birth. It is, therefore, not possible to formulate guidelines from current data. These further diagnostics and intervention should only be done by an experienced multidisciplinary team in a specialized center of prenatal care after a careful benefit-risk evaluation. Determination of the indications and optimal modes of prenatal treatment for nonimmune fetal goitrous hypothyroidism will require larger well-designed studies that would be best conducted through international cooperation between multidisciplinary medical teams. Alternative ways of treating the fetus by administering drugs to the mother should also be investigated. In a hypothyroid pregnant woman, the preferred approach is to treat the woman with (rather than the fetus) with LT4. Finally, adequate iodine intake should be ensured for all pregnant women $(250 \mu \mathrm{g} /$ day $)$.

\section{CONCLUSIONS}

This update of the consensus guidelines on $\mathrm{CH}$ recommends worldwide neonatal screening and appropriate diagnostics - including genetics - to assess the cause of both primary and central hypothyroidism. The expert panel recommends the immediate start of correctly dosed LT4 treatment, and frequent follow-up including laboratory testing and dose adjustments to keep TH levels in their target ranges, timely assessments of the need to continue treatment, attention for neurodevelopmental and neurosensory functions and, if necessary, consulting other health professionals, and education of the child and family about $\mathrm{CH}$. Harmonization of diagnostics, treatment, and follow-up will optimize patient outcomes. Lastly, all individuals with $\mathrm{CH}$ are entitled to a well-planned transition of care from pediatrics to adult medicine. This consensus guidelines update should be used to further optimize detection, diagnosis, treatment, and follow-up of children with all forms of $\mathrm{CH}$ in the light of the most recent evidence. It should be helpful in convincing health authorities of the benefits of neonatal screening for $\mathrm{CH}$. Despite $\sim 50$ years of neonatal screening for $\mathrm{CH}$, some important questions remain, such as the genetic etiology of TD, the assumed harm of subclinical $\mathrm{CH}$, that is, a normal fT4 in combination with an elevated $\mathrm{TSH}$, and the cause of the gradually increased incidence of $\mathrm{CH}$ with GIS. Further epidemiological and experimental studies are needed to understand the increased incidence of this condition.

\section{AUTHOR DISCLOSURE STATEMENT}

Part of the scientific study performed by A.S. and M.P. in relation to congenital hypothyroidism was financed by grants from EDF, Sandoz SAS Merck Serono France, and nonprofit 
Princess Grace Foundation of Monaco as well as by French public nonprofit funding agency Programme Hospitalier de Recherche Clinique (ClinicalTrial.gov: NCT01916018, P110120 - IDRCB 2012-A00797-36). A.S. was supported by the European Society for Paediatric Endocrinology Research Fellowship Grant and Alexander S. Onassis Foundation. The financing bodies were not involved in reviewing the content of this article. The remaining authors of the article have no conflicts of interest to declare related to the guideline content.

\section{FUNDING INFORMATION}

One of the two face-to-face meetings necessary to achieve this study was supported by a grant from the ENDO-ERN.

\section{REFERENCES}

1. Léger J, Olivieri A, Donaldson M, Torresani T, Krude H, van Vliet G, Polak M, Butler G; ESPE-PES-SLEP-JSPEAPEG-APPES-ISPAE; Congenital Hypothyroidism Consensus Conference Group 2014 European Society for Paediatric Endocrinology consensus guidelines on screening, diagnosis, and management of congenital hypothyroidism. J Clin Endocrinol Metab 99:363-384.

2. Swiglo BA, Murad MH, Schunemann HJ, Kunz R, Vigersky RA, Guyatt GH, Montori VM 2008 Case for clarity, consistency, and helpfulness: state-of-the-art clinical practice guidelines in endocrinology using the grading of recommendations, assessment, development, and evaluation system. J Clin Endocrinol Metab 93:666-673.

3. Hulse JA 1984 Outcome for congenital hypothyroidism. Arch Dis Child 59:23-29.

4. Alm J, Larsson A, Zetterstrom R 1981 Congenital hypothyroidism in Sweden. Psychomotor development in patients detected by clinical signs and symptoms. Acta Paediatr Scand 70:907-912.

5. Geelhoed EA, Lewis B, Hounsome D, O'Leary P 2005 Economic evaluation of neonatal screening for phenylketonuria and congenital hypothyroidism. J Paediatr Child Health 41:575-579.

6. Ford G, LaFranchi SH 2014 Screening for congenital hypothyroidism: a worldwide view of strategies. Best Pract Res Clin Endocrinol Metab 28:175-187.

7. Barnes ND 1985 Screening for congenital hypothyroidism: the first decade. Arch Dis Child 60:587-592.

8. Langham S, Hindmarsh P, Krywawych S, Peters C 2013 Screening for congenital hypothyroidism: comparison of borderline screening cut-off points and the effect on the number of children treated with levothyroxine. Eur Thyroid J 2:180-186.

9. Olivieri A, Fazzini C, Medda E; Italian Study Group for Congenital Hypothyroidism 2015 Multiple factors influencing the incidence of congenital hypothyroidism detected by neonatal screening. Horm Res Paediatr 83: 86-93.

10. Mitchell ML, Hsu HW, Sahai I; Massachusetts Pediatric Endocrine Work Group 2011 The increased incidence of congenital hypothyroidism: fact or fancy? Clin Endocrinol (Oxf) 75:806-810.

11. Corbetta C, Weber G, Cortinovis F, Calebiro D, Passoni A, Vigone MC, Beck-Peccoz P, Chiumello G, Persani L 2009 A 7-year experience with low blood TSH cutoff levels for neonatal screening reveals an unsuspected fre- quency of congenital hypothyroidism. Clin Endocrinol (Oxf) 71:739-745.

12. Barry Y, Bonaldi C, Goulet V, Coutant R, Léger J, Paty AC, Delmas D, Cheillan D, Roussey M 2016 Increased incidence of congenital hypothyroidism in France from 1982 to 2012: a nationwide multicenter analysis. Ann Epidemiol 26:100-105.

13. Albert BB, Cutfield WS, Webster D, Carll J, Derraik JG, Jefferies C, Gunn AJ, Hofman PL 2012 Etiology of increasing incidence of congenital hypothyroidism in New Zealand from 1993-2010. J Clin Endocrinol Metab 97: 3155-3160.

14. Peters C, Brooke I, Heales S, Ifederu A, Langham S, Hindmarsh P, Cole TJ 2016 Defining the newborn blood spot screening reference interval for TSH: impact of ethnicity. J Clin Endocrinol Metab 101:3445-3449.

15. Persani L, Rurale G, de Filippis T, Galazzi E, Muzza M, Fugazzola L 2018 Genetics and management of congenital hypothyroidism. Best Pract Res Clin Endocrinol Metab 32:387-396.

16. Peters C, Nicholas AK, Schoenmakers E, Lyons G, Langham S, Serra EG, Sebire NJ, Muzza M, Fugazzola L, Schoenmakers N 2019 DUOX2/DUOXA2 mutations frequently cause congenital hypothyroidism which evades detection on UK newborn screening. Thyroid 29:790-801.

17. Knowles RL, Oerton J, Cheetham T, Butler G, Cavanagh C, Tetlow L, Dezateux C 2018 Newborn screening for primary congenital hypothyroidism: estimating test performance at different TSH thresholds. J Clin Endocrinol Metab 103:3720-3728.

18. Dufort G, Larrivée-Vanier S, Eugène D, De Deken X, Seebauer B, Heinimann K, Lévesque S, Gravel S, Szinnai G, Van Vliet G, Deladoëy J 2019 Wide spectrum of DUOX2 deficiency: from life-threatening compressive goiter in infancy to lifelong euthyroidism. Thyroid 29: 1018-1022.

19. Lain S, Trumpff C, Grosse SD, Olivieri A, Guy Van Vliet G 2017 Are lower TSH cutoffs in neonatal screening for congenital hypothyroidism warranted? Eur J Endocrinol 177:D1-D12.

20. Zwaveling-Soonawala N, van Trotsenburg AS, Verkerk PH 2015 The severity of congenital hypothyroidism of central origin should not be underestimated. J Clin Endocrinol Metab 100:297-300.

21. Nebesio TD, McKenna MP, Nabhan ZM, Eugster EA 2010 Newborn screening results in children with central hypothyroidism. J Pediatr 156:990-993.

22. Braslavsky D, Méndez MV, Prieto L, Keselman A, Enacan R, Gruñeiro-Papendieck L, Jullien N, Savenau A, Reynaud R, Brue T, Bergadá I, Chiesa A 2017 Pilot neonatal screening program for central congenital hypothyroidism: evidence of significant detection. Horm Res Paediatr 88:274-280.

23. Adachi M, Soneda A, Asakura Y, Muroya K, Yamagami Y, Hirahara F 2012 Mass screening of newborns for congenital hypothyroidism of central origin by free thyroxine measurement of blood samples on filter paper. Eur J Endocrinol 166:829-838.

24. Kempers MJ, Lanting CI, van Heijst AF, van Trotsenburg AS, Wiedijk BM, de Vijlder JJ, Vulsma T 2006 Neonatal screening for congenital hypothyroidism based on thyroxine, thyrotropin, and thyroxine-binding globulin measurement: potentials and pitfalls. J Clin Endocrinol Metab 91:3370-3376. 
25. Persani L, Brabant G, Dattani M, Bonomi M, FeldtRasmussen U, Fliers E, Gruters A, Maiter D, Schoenmakers N, van Trotsenburg ASP 2018 European Thyroid Association (ETA) Guidelines on the diagnosis and management of central hypothyroidism. Eur Thyroid J 7:225-237.

26. Lanting CI, van Tijn DA, Loeber JG, Vulsma T, de Vijlder JJ, Verkerk PH 2005 Clinical effectiveness and cost-effectiveness of the use of the thyroxine/thyroxinebinding globulin ratio to detect congenital hypothyroidism of thyroidal and central origin in a neonatal screening program. Pediatrics 116:168-173.

27. Groeneweg S, Peeters RP, Moran C, Stoupa A, Auriol F, Tonduti D, Dica A, Paone L, Rozenkova K, Malikova J, van der Walt A, de Coo IFM, McGowan A, Lyons G, Aarsen FK, Barca D, van Beynum IM, van der Knoop MM, Jansen J, Manshande M, Lunsing RJ, Nowak S, den Uil CA, Zillikens MC, Visser FE, Vrijmoeth $\mathrm{P}$, de Wit MCY, Wolf NI, Zandstra A, Ambegaonkar G, Singh Y, de Rijke YB, Medici M, Bertini ES, Depoorter S, Lebl J, Cappa M, De Meirleir L, Krude H, Craiu D, Zibordi F, Oliver Petit I, Polak M, Chatterjee K, Visser TJ, Visser WE 2019 Effectiveness and safety of the tri-iodothyronine analogue Triac in children and adults with MCT8 deficiency: an international, single-arm, open-label, phase 2 trial. Lancet Diabetes Endocrinol 7:695-706.

28. Zung A, Bier Palmon R, Golan A, Troitzky M, EventovFriedman S, Marom R, Keidar R, Kats N, Almashanu S, Flidel-Rimon O 2017 Risk factors for the development of delayed TSH elevation in neonatal intensive care unit newborns. J Clin Endocrinol Metab 102:3050-3055.

29. McGrath N, Hawkes CP, Mayne P, Murphy NP 2019 Optimal timing of repeat newborn screening for congenital hypothyroidism in preterm infants to detect delayed thyroid-stimulating hormone elevation. J Pediatr 205: 77-82.

30. Cavarzere P, Camilot M, Popa FI, Lauriola S, Teofoli F, Gaudino R, Vincenzi M, Antoniazzi F 2016 Congenital hypothyroidism with delayed TSH elevation in low-birthweight infants: incidence, diagnosis and management. Eur J Endocrinol 175:395-402.

31. LaFranchi SH 2014 Screening preterm infants for congenital hypothyroidism: better the second time around. J Pediatr 164:1259-1261.

32. Murphy N, Hume R, van Toor H, Matthews TG, Ogston SA, Wu SY, Visser TJ, Williams FL 2004 The hypothalamic-pituitary-thyroid axis in preterm infants: changes in the first 24 hours of postnatal life. J Clin Endocrinol Metab 89:2824-2833.

33. Aitken J, Willimas FLR 2014 A systematic review of thyroid dysfunction in preterm neonates exposed to topical iodine. Arch Dis Child Fetal Neonatal Ed 99:21-28.

34. Olivieri A, Medda E, De Angelis S, Valensise H, De Felice M, Fazzini C, Cascino I, Cordeddu V, Sorcini M, Stazi MA; Study Group for Congenital Hypothyroidism 2007 High risk of congenital hypothyroidism in multiple pregnancies. J Clin Endocrinol Metab 92:3141-3147.

35. Perry R, Heinrichs C, Bourdoux P, Khoury K, Szöts F, Dussault JH, Vassart G, Van Vliet G 2002 Discordance of monozygotic twins for thyroid dysgenesis: implications for screening and for molecular pathophysiology. J Clin Endocrinol Metab 87:4072-4077.

36. Medda E, Vigone MC, Cassio A, Calaciura F, Costa P, Weber G, de Filippis T, Gelmini G, Di Frenna M, Caiulo S, Ortolano R, Rotondi D, Bartolucci M, Gelsomino R, De
Angelis S, Gabbianelli M, Persani L, Olivieri A 2019 Neonatal screening for congenital hypothyroidism: what can we learn from discordant twins? J Clin Endocrinol Metab 104:5765-5779.

37. Fort P, Lifshitz F, Bellisario R, Davis J, Lanes R, Pugliese M, Richman R, Post EM, David R 1984 Abnormalities of thyroid function in infants with Down syndrome. J Pediatr 104:545-549.

38. Sharav T, Collins RM Jr, Baab PJ 1988 Growth studies in infants and children with Down's syndrome and elevated levels of thyrotropin. Am J Dis Child 142:1302-1306.

39. Purdy IB, Singh N, Brown WL, Vangala S, Devaskar UP 2014 Revisiting early hypothyroidism screening in infants with Down syndrome. J Perinatol 34:936-940.

40. van Trotsenburg AS, Vulsma T, van Santen HM, Cheung W, de Vijlder JJ 2003 Lower neonatal screening thyroxine concentrations in down syndrome newborns. J Clin Endocrinol Metab 88:1512-1515.

41. van Trotsenburg AS, Kempers MJ, Endert E, Tijssen JG, de Vijlder JJ, Vulsma T 2006 Trisomy 21 causes persistent congenital hypothyroidism presumably of thyroidal origin. Thyroid 16:671-680.

42. Kariyawasam D, Rachdi L, Carré A, Martin M, Houlier M, Janel N, Delabar JM, Scharfmann R, Polak M 2015 DYRK1A BAC transgenic mouse: a new model of thyroid dysgenesis in Down syndrome. Endocrinology 156:11711180.

43. Zwaveling-Soonawala N, Witteveen ME, Marchal JP, Klouwer FCC, Ikelaar NA, Smets AMJB, van Rijn RR, Endert E, Fliers E, van Trotsenburg ASP 2017 Early thyroxine treatment in Down syndrome and thyroid function later in life. Eur J Endocrinol 176:505-513.

44. van Trotsenburg AS, Heymans HS, Tijssen JG, de Vijlder JJ, Vulsma T 2006 Comorbidity, hospitalization, and medication use and their influence on mental and motor development of young infants with Down syndrome. Pediatrics 118: 1633-1639.

45. Persani L, Cangiano B, Bonomi M 2019 The diagnosis and management of central hypothyroidism in 2018. Endocr Connect 8:44-54.

46. Zwaveling-Soonawala N, van Trotsenburg ASP, Verkerk PH 2018 TSH and FT4 Concentrations in congenital central hypothyroidism and mild congenital thyroidal hypothyroidism. J Clin Endocrinol Metab 103:13421348.

47. Delvecchio M, Vigone MC, Wasniewska M, Weber G, Lapolla R, Popolo PP, Tronconi GM, Di Mase R, De Luca F, Cavallo L, Salerno M, Faienza MF 2015 Final height in Italian patients with congenital hypothyroidism detected by neonatal screening: a 20 -year observational study. Ital J Pediatr 41:82.

48. Wassner AJ 2018 Congenital hypothyroidism. Clin Perinatol 45:1-18.

49. Wassner AJ 2017 Pediatric hypothyrodism. Paediatr Drugs 19:291-301.

50. Vigone MC, Capalbo D, Weber G, Salerno M 2018 Mild hypothyroidism in childhood: who, when, and how should be treated? J Endocr Soc 2:1024-1039.

51. Lain SJ, Bentley JP, Wiley V, Roberts CL, Jack M, Wilcken B, Nassar N 2016 Association between borderline neonatal thyroid-stimulating hormone concentrations and educational and developmental outcomes: a population-based record-linkage study. Lancet Diabetes Endocrinol 4:756-765. 
52. Trumpff C, de Schepper J, Vanderfauillie J, Vercruysse N, Van Oyen H, Moreno-Reyes R, Tafforeau J, Vanderpas J, Vandevijvere S 2015 Thyroid-stimulating hormone (TSH) concentration at birth in Belgian neonates and cognitive development at preschool age. Nutrients 7:9018-9032.

53. Trumpff C, de Schepper J, Vanderfauillie J, Vercruysse N, Van Oyen H, Moreno-Reyes R, Tafforeau J, Vandevijvere S 2016 Neonatal thyroid-stimulating hormone concentration and psychomotor development at preschool age. Arch Dis Child 101: 1100-1106.

54. Cherella CE, Wasser AJ 2017 Congenital hypothyroidism: insights into pathogenesis and treatment. Int $\mathrm{J}$ Pediatr Endocrinol 2017:11.

55. Leung AKC, Leung AAC 2019 Evaluation and management of the child with hypothyroidism. World J Pediatr 15:124-134.

56. van Tijn D, de Vijder JJM, Verbeeten B, Verkerk P, Vulsma T 2005 Neonatal detection of congenital hypothyroidism of central origin. J Clin Endocrinol Metab 90: 3350-3359.

57. Salm N, Yetter E, Tluczek A 2012 Informing parents about positive newborn screen results: parents' recommendations. J Child Health Care 16:367-381.

58. Cassio A, Corbetta C, Antonozzi I, Calaciura F, Caruso U, Cesaretti G, Gastaldi R, Medda E, Mosca F, Pasquini E, Salerno MC, Stoppioni V, Tonacchera M, Weber G, Olivieri A; Italian Society for Pediatric Endocrinology and Diabetology; Italian Society for the Study of Metabolic Diseases and Neonatal Screening; Italian National Institute of Health; Italian National Coordinating Group for Congenital Hypothyroidism; Italian Thyroid Association; Italian Society of Pediatrics; Italian Society of Neonatology; Italian Society of Endrocrinology; Associazione Medici Endocrinologi 2013 The Italian screening program for primary congenital hypothyroidism: actions to improve screening, diagnosis, follow-up, and surveillance. J Endocrinol Invest 36:195-203.

59. Hettiarachchi M, Amarasena S 2014 Indicators of newborn screening for congenital hypothyroidism in Sri Lanka: program challenges and way forward. BMC Health Serv Res 14:385.

60. Supakul N, Delaney LR, Siddiqui AR, Jennings SG, Eugster EA, Karmazyn B 2012 Ultrasound for primary imaging of congenital hypothyroidism. AJR Am J Roentgenol 199:360-366.

61. Chanoine JP, Toppet V, Lagasse R, Spehl M, Delange F 1991 Determination of thyroid volume by ultrasound from the neonatal period to late adolescence. Eur J Pediatr 150: 395-399.

62. Perry RJ, Hollman AS, Wood AM, Donaldson MD 2002 Ultrasound of the thyroid gland in the newborn: normative data. Arch Dis Child Fetal Neonatal Ed 87:F209-F211.

63. Freire R, Monte O, Tomimori EK, Catarino RM, Sterza T, Rocha T, Pereira KCC, Mattos HS, Jr., Fagundes LB, Liberato MM, Dos Santos LWR, Pereira A, Cintra T, Hegner C, Lube D, Murad M 2015 Sonographic evaluation of the thyroid size in neonates. J Clin Ultrasound 43: 224-229.

64. Clerc J 2014 Imaging the thyroid in children. Best Pract Res Clin Endocrinol Metab 28:203-220.

65. Keller-Petrot I, Leger J, Sergent-Alaoui A, de LabriolleVaylet C 2017 Congenital hypothyroidism: role of nuclear medicine. Semin Nucl Med 47:135-142.
66. Graber E, Regelmann MO, Annunziato R, Machac J, Rapaport R 2015 The role of (1)(2)(3)I imaging in the evaluation of infants with mild congenital hypothyroidism. Horm Res Paediatr 83:94-101.

67. Goldis M, Waldman L, Marginean O, Rosenberg HK, Rapaport R 2016 Thyroid imaging in infants. Endocrinol Metab Clin North Am 45:255-266.

68. Fugazzola L, Persani L, Vannucchi G, Carletto M, Mannavola D, Vigone MC, Cortinovis F, Beccaria L, Longari V, Weber G, Beck-Peccoz P 2007 Thyroid scintigraphy and perchlorate test after recombinant human TSH: a new tool for the differential diagnosis of congenital hypothyroidism during infancy. Eur J Nucl Med Mol Imaging 34: 1498-1503.

69. De Silva A, Jong I, McLean G, Bergman P, Rodda C, Brown J, Nandurkar D 2014 The role of scintigraphy and ultrasound in the imaging of neonatal hypothyroidism: 5year retrospective review of single-centre experience. J Med Imaging Radiat Oncol 58:422-430.

70. Wasniewska M, De Luca F, Cassio A, Oggiaro N, Gianino P, Delvecchio M, Aiazzi R, Stoppioni V, Lombardo F, Messina MF, Valenzise M, Arrigo T 2003 In congenital hypothyroidism bone maturation at birth may be a predictive factor of psychomotor development during the first Year of life irrespective of other variables related to treatment. Eur J Endocrinol 149:1-6.

71. Léger J, Ecosse E, Roussey M, Lanoë JL, Larroque B 2011 Subtle health impairment and socioeducational attainment in young adult patients with congenital hypothyroidism diagnosed by neonatal screening: a longitudinal populationbased cohort study. J Clin Endocrinol Metab 96:17711782.

72. Lichtenberger-Geslin L, Dos Santos S, Hassani Y, Ecosse E, Van Den Abbeele T, Léger J 2013 Factors associated with hearing impairment in patients with congenital hypothyroidism treated since the neonatal period: a national population-based study. J Clin Endocrinol Metab 98: 3644-3652.

73. Salerno M, Militerni R, Bravaccio C, Micillo M, Capalbo D, Di MS, Tenore A 2002 Effect of different starting doses of levothyroxine on growth and intellectual outcome at four years of age in congenital hypothyroidism. Thyroid 12:45-52.

74. Bamforth JS, Hughes IA, Lazarus JH, Weaver CM, Harper PS 1989 Congenital hypothyroidism, spiky hair, and cleft palate. J Med Genet 26:49-51.

75. Devriendt K, Vanhole C, Matthijs G, de Zegher F 1998 Deletion of thyroid transcription factor-1 gene in an infant with neonatal thyroid dysfunction and respiratory failure. N Engl J Med 338:1317-1318.

76. Krude H, Schutz B, Biebermann H, von Moers A, Schnabel D, Neitzel H, Tonnies H, Weise D, Lafferty A, Schwarz S, DeFelice M, von Deimling A, van Landeghem F, DiLauro R, Gruters A 2002 Choreoathetosis, hypothyroidism, and pulmonary alterations due to human NKX2-1 haploinsufficiency. J Clin Invest 109:475-480.

77. de Filippis T, Marelli F, Nebbia G, Porazzi P, Corbetta S, Fugazzola L, Gastaldi R, Vigone MC, Biffanti R, Frizziero D, Mandara L, Prontera P, Salerno M, Maghnie M, Tiso N, Radetti G, Weber G, Persani L 2016 JAG1 lossof-function variations as a novel predisposing event in the pathogenesis of congenital thyroid defects. J Clin Endocrinol Metab 101:861-870. 
78. Levy-Shraga Y, Gothelf D, Pinchevski-Kadir S, Katz U, Modan-Moses D 2018 Endocrine manifestations in children with Williams-Beuren syndrome. Acta Paediatr 107:678-684.

79. Shugar AL, Shapiro JM, Cytrynbaum C, Hedges S, Weksberg R, Fishman L 2015 An increased prevalence of thyroid disease in children with 22q11.2 deletion syndrome. Am J Med Genet A 167:1560-1564.

80. Kawame H, Hannibal MC, Hudgins L, Pagon RA 1999 Phenotypic spectrum and management issues in Kabuki syndrome. J Pediatr 134:480-485.

81. Zenker M, Mayerle J, Lerch MM, Tagariello A, Zerres K, Durie PR, Beier M, Hulskamp G, Guzman C, Rehder H, Beemer FA, Hamel B, Vanlieferinghen P, GershoniBaruch R, Vieira MW, Dumic M, Auslender R, Gil-daSilva-Lopes VL, Steinlicht S, Rauh M, Shalev SA, Thiel C, Ekici AB, Winterpacht A, Kwon YT, Varshavsky A, Reis A 2005 Deficiency of UBR1, a ubiquitin ligase of the $\mathrm{N}$-end rule pathway, causes pancreatic dysfunction, malformations and mental retardation (Johanson-Blizzard syndrome). Nat Genet 37:1345-1350.

82. Kumar J, Gordillo R, Kaskel FJ, Druschel CM, Woroniecki RP 2009 Increased prevalence of renal and urinary tract anomalies in children with congenital hypothyroidism. J Pediatr 154:263-266.

83. Roberts HE, Moore CA, Fernhoff PM, Brown AL, Khoury MJ 1997 Population study of congenital hypothyroidism and associated birth defects, Atlanta, 1979-1992. Am J Med Genet 71:29-32.

84. Devos H, Rodd C, Gagne N, Laframboise R, Van Vliet G 1999 A search for the possible molecular mechanisms of thyroid dysgenesis: sex ratios and associated malformations. J Clin Endocrinol Metab 84:2502-2506.

85. Castanet M, Polak M, Bonaïti-Pellié C, Lyonnet S, Czernichow P, Léger J, AFDPHE (Association Française pour le Dépistage et la Prévention des Handicaps de l'Enfant) 2001 Nineteen years of national screening for congenital hypothyroidism: familial cases with thyroid dysgenesis suggest the involvement of genetic factors. J Clin Endocrinol Metab 86:2009-2014.

86. Olivieri A, Stazi MA, Mastroiacovo P, Fazzini C, Medda E, Spagnolo A, De Angelis S, Grandolfo ME, Taruscio D, Cordeddu V, Sorcini M; Study group for congenital hypothyroidism 2002 A population-based study on the frequency of additional congenital malformations in infants with congenital hypothyroidism: data from the Italian Registry for Congenital Hypothyroidism (1991-1998). J Clin Endocrinol Metab 87:557-562.

87. Azar-Kolakez A, Ecosse E, Dos Santos S, Leger J 2013 All-cause and disease-specific mortality and morbidity in patients with congenital hypothyroidism treated since the neonatal period: a national population-based study. J Clin Endocrinol Metab 98:785-793.

88. Bas VN, Ozgelen S, Cetinkaya S, Aycan Z 2014 Diseases accompanying congenital hypothyroidism. J Pediatr Endocrinol Metab 27:485-489.

89. de Filippis T, Gelmini G, Paraboschi E, Vigone MC, Di Frenna M, Marelli F, Bonomi M, Cassio A, Larizza D, Moro M, Radetti G, Salerno M, Ardissino D, Weber G, Gentilini D, Guizzardi F, Duga S, Persani L 2017 A frequent oligogenic involvement in congenital hypothyroidism. Hum Mol Genet 26:2507-2514.

90. Albert BB, Heather N, Derraik JG, Cutfield WS, Wouldes T, Tregurtha S, Mathai S, Webster D, Jefferies C, Gunn
AJ, Hofman PL 2013 Neurodevelopmental and body composition outcomes in children with congenital hypothyroidism treated with high-dose initial replacement and close monitoring. J Clin Endocrinol Metab 98:36633670 .

91. Aleksander PE, Brückner-Spieler M, Stoehr AM, Lankes E, Kühnen P, Schnabel D, Ernert A, Stäblein W, Craig ME, Blankenstein O, Grüters A, Krude H 2018 Mean high-dose 1-thyroxine treatment is efficient and safe to achieve a normal IQ in young adult patients with congenital hypothyroidism. J Clin Endocrinol Metab 103: 1459-1469.

92. Cassio A, Monti S, Rizzello A, Bettocchi I, Baronio F, D'Addabbo G, Bal MO, Balsamo A 2013 Comparison between liquid and tablet formulations of levothyroxine in the initial treatment of congenital hypothyroidism. J Pediatr 162:1264-1269.

93. Peroni E, Vigone MC, Mora S, Bassi LA, Pozzi C, Passoni A, Weber G 2014 Congenital hypothyroidism treatment in infants: a comparative study between liquid and tablet formulations of levothyroxine. Horm Res Paediatr 81:50-54.

94. Carswell JM, Gordon JH, Popovsky E, Hale A, Brown RS 2013 Generic and brand-name L-thyroxine are not bioequivalent for children with severe congenital hypothyroidism. J Clin Endocrinol Metab 98:610-617.

95. Vogiatzi MG, Kirkland JL1997 Frequency and necessity of thyroid function tests in neonates and infants with congenital hypothyroidism. Pediatrics 100:E6.

96. Mathai S, Cutfield WS, Gunn AJ, Webster D, Jefferies C, Robinson E, Hofman P 2008 A novel therapeutic paradigm to treat congenital hypothyroidism. Clin Endocrinol (Oxf) 69:142-147.

97. Balhara B, Misra M, Levitsky LL 2001 Clinical monitoring guidelines for congenital hypothyroidism: laboratory outcome data in the first year of life. J Pediatr 158: 532-537.

98. Baloch Z, Carayon P, Conte-Delvox B, Demers LM, Feldt-Rasmussen U, Henry JF, LiVosli VA, Niccoli-Sire P, John R, Ruf J, Smyth PP, Spencer CA, Stockigt JR, Guidelines Committee, National Academy of Clinical Biochemistry 2003 Laboratory medicine practice guidelines. Laboratory support for the diagnosis and monitoring of thyroid disease. Thyroid 13:3-126.

99. Bakker B, Kempers MJE, De Vijlder JJM, Van Tijn DA, Wiedijk BM, Van Bruggen M, Vulsma T 2002 Dynamics of the plasma concentrations of TSH, FT4 and T3 following thyroxine supplementation in congenital hypothyroidism. Clin Endocrinol 57:529-537.

100. Selva KA, Mandel SH, Rien L, Sesser D, Miyahira R, Skeels M, Nelson JC, Lafranchi SH 2002 Initial treatment dose of L-thyroxine in congenital hypothyroidism. J Pediatr 141:786-792.

101. Selva KA, Harper A, Downs A, Blasco PA, Lafranchi SH 2005 Neurodevelopmental outcomes in congenital hypothyroidism: comparison of initial $\mathrm{T} 4$ dose and time to reach target T4 and TSH. J Pediatr 147:775-780.

102. Heyerdahl S, Oerbeck B 2003 Congenital hypothyroidism: developmental outcome in relation to levothyroxine treatment variables. Thyroid 13:1029-1038.

103. Hanukoglu A, Perlman K, Shamis I, Brnjac L, Rovet J, Daneman D 2001 Relationship of etiology to treatment in congenital hypothyroidism. J Clin Endocrinol Metab 86: 186-191. 
104. Zdraveska N, Anastasovska V, Kocova M 2016 Frequency of thyroid status monitoring in the first year of life and predictors for more frequent monitoring in infants with congenital hypothyroidism. J Pediatr Endocrinol Metab 29:795-800.

105. Tuhan H, Abaci A, Cicek G, Anik A, Catli G, Demir K, Bober E 2016 Levothyroxine replacement in primary congenital hypothyroidism: the higher the initial dose then higher the rate of overtreatment. J Pediatr Endocrinol metab 29:133-138.

106. Schoelwer MJ, Tu W, Zhou J, Eugster EA 2017 Targeted levothyroxine therapy for treatment of congenital hypothyroidism. Endocrine Pract 23:1067-1071.

107. Craven M, Frank GFR 2018 Does initial dosing of levothyroxine in infants with congenital hypothyroidism lead to frequent dose adjustments secondary to iatrogenic hyperthyroidism on follow-up? J Pediatr Endocrinol Metab 31:597-600.

108. Bongers-Schokking JJ, Resing WCM, de Rijke YB, de Ridder MAJ, de Muinck Keizer-Schraman SMPF 2013 Cognitive development in congenital hypothyroidism: is overtreatment a greater threat than undertreatment? J Clin Endocrinol Metab 98:4499-4506.

109. Bongers-Schokking JJ, Resing WCM, Oostdijk W, de Rijke YB, de Muinck Keizer-Schraman SMPF 2018 Relation between early over- and undertreatment and behavioural problems in preadolescent children with congenital hypothyroidism. Horm Res Paediatr 90:247-956.

110. Rovet JF, Alvarez M 1996 Thyroid hormone and attention in congenital hypothyroidism. J Pediatr Endocrinol Metab 9:63-66.

111. Fisher DA, Schoen EJ, LaFranchi S, Mandel SH, Nelson JC, Carlton EL, Goshi JH 2000 The hypothalamicpituitary negative feedback control axis in children with treated congenital hypothyroidism. J Clin Endocrinol Metab 85:2722-2727.

112. Bagattini B, Cosmo CD, Montanelli L, Piaggi P, Ciampi M, Agretti P, Marco GD, Vitti P, Tonacchera M 2014 The different requirement of L-T4 therapy in congenital athyreosis compared with adult-acquired hypothyroidism suggests a persisting thyroid hormone resistance at the hypothalamic-pituitary level. Eur J Endocrinol 171:615621.

113. American Academy of Pediatrics, Rose SR; Section on Endocrinology and Committee on Genetics, American Thyroid Association, Brown RS: Public health Committee, Lawson Wilkins Pediatric Endocrine Society, Foley T, Kaplowitz PB, Kaye CL, Sundararjan S, Varma SK 2006 Update on newborn screening and therapy for congenital hypothyroidism. Pediatrics 117:22902303.

114. Léger J 2015 A clinical update of long-term outcome in young adults. Eur J Endocrinol 172:67-77.

115. Strickler C, Pilon AF 2007 Presumed levothyroxine-induced pseudotumor cerebri in a pediatric patient treated for congenital hypothyroidism. Clin Ophthalmol 1:545-549.

116. Penfold JL, Simpson DA 1975 Premature craniosynostosisa complication of thyroid replacement therapy. J Pediatr 86:360-363.

117. Dubuis JM, Glorieux J, Richer F, Deal CL, Dussault JH, Van Vliet G 1996 Outcome of severe congenital hypothyroidism: closing the developmental gap with early high dose levothyroxine treatment. J Clin Endocrinol Metab 81:222-227.
118. Stone E, Leiter LA, Lambert JR, Silverberg JD, Jeejeebhoy KN, Burrow GN 1984 L-thyroxine absorption in patients with short bowel syndrome. J Clin Endocrinol Metab 59:139-141.

119. Ybarra ML, Dos Santos TJ, Pinheiro CTC, Dichtchekenian V, Damiani D 2018 Rectal levothyroxine for the treatment of hypothyroidism: a case study. Pediatrics 142: e20173317.

120. Huang SA, Tu HM, Harney JW, Venihaki M, Butte AJ, Kozakewich HP, Fishman SJ, Larsen PR 2000 Severe hypothyroidism caused by type 3 iodothyronine deiodinase in infantile hemangiomas. $\mathrm{N}$ Engl J Med 343: 185-189.

121. Bessho K, Etani Y, Ichimori H, Miyoshi Y, Namba N, Yoneda A, Ooue T, Chihara T, Morii E, Aoki T, Murakami M, Mushiake S, Ozono K 2010 Increased type 3 iodothyronine deiodinase activity in a regrown hepatic hemangioma with consumptive hypothyrodism. Eur J Pediatr 169:215-221.

122. Peters C, Langham S, Mullis PE, Dattani MT 2010 Use of combined liothyronine and thyroxine therapy for consumptive hypothyroidism associated with hepatic haemangiomas in infancy. Horm Res Paediatr 74:149-152.

123. Zeitler P, Solberg P 2010 Pharmacy and therapeutics committee of the Lawson Wilkins Pediatric Endocrine Society. J Pediatr 157:13-14.

124. Colucchi P, Yue CS, Ducharme M, Benvenga S 2013 A review of the pharmacokinetics of levothyroxine for the treatment of hypothyroidism. Eur Endocrinol 9: 40-47.

125. Jonklaas J, Bianco AC, Bauer AJ, Burman KD, Cappola AR, Celi FS, Cooper DS, Kim BW, Peeters RP, Rosenthal MS, Sawka AM, American Thyroid Association Task Force on thyroid hormone replacement 2014 Guidelines for the treatment of hypothyroidism: prepared by the American Thyroid Association task force on thyroid hormone replacement. Thyroid 24:1670-1651.

126. Chaker L, Bianco AC, Jonklaas J, Peeters RP 2017 Hypothyroidism. Lancet 390:1550-1562.

127. Chorazy PA, Himelhoch S, Hopwood NJ, Gregor NG, Postellon DC 1995 Persistent hypothyroidism in an infant receiving a soy formula: case report and review of the literature. Pediatrics 96:148-150.

128. Jabbar MA, Larrea J, Shaw RA 1997 Abnormal thyroid function tests in infants with congenital hypothyroidism: the influence of soy-based formula. J Am Coll Nutr 16: 280-282.

129. Slawik M, Klawitter B, Meiser E, Schories M, Zwermann O, Borm K, Peper M, Lubrich B, Hug MJ, Nauck M, Olschewski M, Beuschlein F, Reincke M 2007 Thyroid hormone replacement for central hypothyroidism: a randomized controlled trial comparing two doses of thyroxine (T4) with a combination of T4 and triiodothyronine. J Clin Endocrinol Metab 92:4115-4122.

130. Koulouri O, Auldin MA, Agarwal R, Kieffer V, Robertson C, Falconer Smith J, Levy MJ, Howlett TA 2011 Diagnosis and treatment of hypothyroidism in TSH deficiency compared to primary thyroid disease: pituitary patients are at risk of under-replacement with levothyroxine. Clin Endocrinol (Oxf) 74:744-749.

131. Peters C, van Trotsenburg ASP, Schoenmakers N 2018 DIAGNOSIS OF ENDOCRINE DISEASE: congenital hypothyroidism: update and perspectives. Eur J Endocrinol 179: 297-317. 
132. Oren A, Wang MK, Brnjac L, Mahmud FH, Palmert MR 2013 Mild neonatal hyperthyrotrophinaemia: 10-year experience suggests the condition is increasingly common but often transient. Clin Endocrinol (Oxf) 79:832-837.

133. Kara C, Gunindi F, Can Yilmaz G, Aydin M 2016 Transient congenital hypothyroidism in Turkey: an analysis on frequency and natural course. J Clin Res Pediatr Endocrinol 8:170-179.

134. Jung JM, Jin HY, Chung ML 2016 Feasibility of an early discontinuation of thyroid hormone treatment in very-lowbirth-weight infants at risk for transient or permanent congenital hypothyroidism. Horm Res Paediatr 85:131139.

135. Korzeniewski SJ, Grigorescu V, Kleyn M, Young WI, Birbeck G, Todem D, Romero R, Paneth N 2013 Transient hypothyroidism at 3-year follow-up among cases of congenital hypothyroidism detected by newborn screening. J Pediatr 162:177-182.

136. Ford GA, Denniston S, Sesser D, Skeels MR, LaFranchi SH 2016 Transient versus permanent congenital hypothyroidism after the age of 3 years in infants detected on the first versus second newborn screening test in Oregon, USA. Horm Res Paediatr 86:169-177.

137. Kang MJ, Chung HR, Oh YJ, Shim YS, Yang S, Hwang IT 2017 Three-year follow-up of children with abnormal newborn screening results for congenital hypothyroidism. Pediatr Neonatol 58:442-448.

138. Park IS, Yoon JS, So CH, Lee HS, Hwang JS 2017 Predictors of transient congenital hypothyroidism in children with eutopic thyroid gland. Ann Pediatr Endocrinol Metab 22:115-118.

139. Zdraveska N, Zdravkovska M, Anastasovska V, Sukarova-Angelovska E, Kocova M 2018 Diagnostic reevaluation of congenital hypothyroidism in Macedonia: predictors for transient or permanent hypothyroidism. Endocr Connect 7:278-285.

140. Fu C, Luo S, Li Y, Li Q, Hu X, Li M, Zhang Y, Su J, Hu X, Chen Y, Wang J, Xie B, Luo J, Fan X, Chen S, Shen Y 2017 The incidence of congenital hypothyroidism $(\mathrm{CH})$ in Guangxi, China and the predictors of permanent and transient CH. Endocr Connect 6:926-934.

141. Razavi Z, Mohammadi L 2017 Permanent and transient congenital hypothyroidism in Hamadan West Province of Iran. Int J Endocrinol Metab 14:e38256.

142. Rabbiosi S, Vigone MC, Cortinovis F, Zamproni I, Fugazzola L, Persani L, Corbetta C, Chiumello G, Weber G 2013 Congenital hypothyroidism with eutopic thyroid gland: analysis of clinical and biochemical features at diagnosis and after re-evaluation. J Clin Endocrinol Metab 98:1395-1402.

143. Olivieri A, Fazzini C, Medda E 2015 Multiple factors influencing the incidence of congenital hypothyroidism detected by neonatal screening. Horm Res Paediatr 83: 86-93.

144. Zung A, Tenenbaum-Rakover Y, Barkan S, Hanukoglu A, Hershkovitz E, Pinhas-Hamiel O, Bistritzer T, Zadik Z 2010 Neonatal hyperthyrotropinemia: population characteristics, diagnosis, management and outcome after cessation of therapy. Clin Endocrinol (Oxf) 72:264-271.

145. Unuvar T, Demir K, Abaci A, Buyukgebiz A, Bober E 2013 The role of initial clinical and laboratory findings in infants with hyperthyrotropinemia to predict transient or permanent hypothyroidism. J Clin Res Pediatr Endocrinol 5:170-173.
146. Messina MF, Aversa T, Salzano G, Zirilli G, Sferlazzas C, De Luca F, Lombardo F 2015 Early discrimination between transient and permanent congenital hypothyroidism in children with eutopic gland. Horm Res Paediatr 84: 159-164.

147. Eugster EA, LeMay D, Zerin JM, Pescovitz OH 2004 Definitive diagnosis in children with congenital hypothyroidism. J Pediatr 144:643-647.

148. Saba C, Guilmin-Crepon S, Zenaty D, Martinerie L, Paulsen A, Simon D, Storey C, Dos Santos S, Haignere J, Mohamed D, Carel JC, Léger J 2018 Early determinants of thyroid function outcomes in children with congenital hypothyroidism and a normally located thyroid gland: a regional cohort study. Thyroid 28:959-967.

149. Oron T, Lazar L, Ben-Yishai S, Tenenbaum A, Yackobovitch-Gavan M, Meyerovitch J, Phillip M, Lebenthal Y 2018 Permanent vs transient congenital hypothyroidism: assessment of predictive variables. J Clin Endocrinol Metab 103:4428-4436.

150. Valizadeh M, Moezzi F, Khavassi Z, Movahedinia M, Mazloomzadeh S, Mehran L 2017 Influence of topical iodine-containing antiseptics used during delivery on recall rate of congenital hypothyroidism screening program. J Pediatr Endocrinol Metab 30:973-978.

151. Chanoine JP, Boulvain M, Bourdoux P, Pardou A, Van Thi HV, Ermans AM, Delange F 1988 Increased recall rate at screening for congenital hypothyroidism in breast fed infants born to iodine overloaded mothers. Arch Dis Child 63:1207-1210.

152. Thaker VV, Galler MF, Marshall AC, Almodovar MC, Hsu HW, Addis CJ, Feldman HA, Brown RS, Levine BS 2017 Hypothyroidism in infants with congenital heart disease exposed to excess iodine. J Endocr Soc 1:10671078.

153. Connelly KJ, Boston BA, Pearce EN, Sesser D, Snyder D, Braverman LE, Pino S, LaFranchi SH 2012 Congenital hypothyroidism caused by excess prenatal maternal iodine ingestion. J Pediatr 161:760-762.

154. Léger J, dos Santos S, Larroque B, Ecosse E 2015 Pregnancy outcomes and relationship to treatment adequacy in women treated early for congenital hypothyroidism: a longitudinal population-based study. J Clin Endocrinol Metab 100:860-869.

155. Alexander EK, Pearce EN, Brent GA, Brown RS, Chen H, Dosiou C, Grobman WA, Laurberg P, Lazarus JH, Mandel SJ, Peeters RP, Sullivan S 20172017 Guidelines of the American Thyroid Association for the diagnosis and management of thyroid disease during pregnancy and the postpartum. Thyroid 27:315-389.

156. Léger J, Forhan A, Dos Santos S, Larroque B, Ecosse E, Charles MA, Heude B 2018 Developmental milestones at one year for the offspring of mothers with congenital hypothyroidism: a population-based study. Eur J Endocrinol 178:471-480.

157. Korevaar TIM, Muetzel R, Medici M, Chaker L, Jaddoe VWV, de Rijke YB, Steegers EAP, Visser TJ, White T, Tiemeier H, Peeters RP 2016 Association of maternal thyroid function during early pregnancy with offspring IQ and brain morphology in childhood: a population-based prospective cohort study. Lancet Diabetes Endocrinol 4: 35-43.

158. Alexander EK, Marqusee E, Lawrence J, Jarolim P, Fischer GA, Larsen PR 2014 Timing and magnitude of in- 
creases in levothyroxine requirements during pregnancy in women with hypothyroidism. N Engl J Med 351:241-24.

159. Simoneau-Roy J, Marti S, Deal C, Huot C, Robaey P, Van Vliet G 2004 Cognition and behavior at school entry in children with congenital hypothyroidism treated early with high-dose levothyroxine. J Pediatr 144:747-752.

160. Bongers-Schokking JJ, de Muinck Keizer-Schrama SM 2005 Influence of timing and dose of thyroid hormone replacement on mental, psychomotor, and behavioral development in children with congenital hypothyroidism. J Pediatr 147:768-774.

161. Grosse SD, Van Vliet G 2011 Prevention of intellectual disability through screening for congenital hypothyroidism: how much and at what level? Arch Dis Child 96: 374-379.

162. Kempers MJ, van der Sluijs Veer L, Nijhuis-van der Sanden RW, Lanting CI, Kooistra L, Wiedijk BM, Last BF, de Vijlder JJ, Grootenhuis MA, Vulsma T 2007 Neonatal screening for congenital hypothyroidism in the Netherlands: cognitive and motor outcome at 10 years of age. J Clin Endocrinol Metab 92:919-924.

163. Rovet JF, Ehrlich R 2000 Psychoeducational outcome in children with early-treated congenital hypothyroidism. Pediatrics 105:515-522.

164. Rovet JF 2005 Children with congenital hypothyroidism and their siblings: do they really differ? Pediatrics 115: $52-57$.

165. Oerbeck B, Sundet K, Kase BF, Heyerdahl S 2003 Congenital hypothyroidism: influence of disease severity and L-thyroxine treatment on intellectual, motor, and school-associated outcomes in young adults. Pediatrics 112:923-930.

166. Dimitropoulos A, Molinari L, Etter K, Torresani T, LangMuritano M, Jenni OG, Largo RH, Latal B 2009 Children with congenital hypothyroidism: long-term intellectual outcome after early high-dose treatment. Pediatr Res 65: 242-248.

167. Hauri-Hohl A, Dusoczky N, Dimitropoulos A, Leuchter RH, Molinari L, Caflisch J, Jenni OG, Latal B 2011 Impaired neuromotor outcome in school-age children with congenital hypothyroidism receiving early high-dose substitution treatment. Pediatr Res 70:614-618.

168. Vulsma T, Gons MH, de Vijlder JJ 1989 Maternal-fetal transfer of thyroxine in congenital hypothyroidism due to a total organification defect or thyroid agenesis. N Engl J Med 321:13-16.

169. Wheeler SM, Willoughby KA, McAndrews MP, Rovet JF 2011 Hippocampal size and memory functioning in children and adolescents with congenital hypothyroidism. J Clin Endocrinol Metab 96:E1427-E1434.

170. Clairman H, Skocic J, Lischinsky JE, Rovet J 2015 Do children with congenital hypothyroidism exhibit abnormal cortical morphology? Pediatr Res 78:286-297.

171. García Morales L, Arnao R, Sánchez R, Íñiguez D, González A 2017 Sustained attention in school-age children with congenital hypothyroidism: influence of episodes of overtreatment in the first three years of life. Neurologia 485:30299-30302.

172. Alvarez M, Iglesias Fernández C, Rodríguez Sánchez A, Dulín Lñiguez E, Rodríguez Arnao MD 2010 Episodes of overtreatment during the first six months in children with congenital hypothyroidism and their relationships with sustained attention and inhibitory control at school age. Horm Res Paediatr 74:114-120.
173. Tillotson SL, Fuggle PW, Smith I, Ades AE, Grant DB 1994 Relation between biochemical severity and intelligence in early treated congenital hypothyroidism: a threshold effect. BMJ 1309:440-445.

174. Salerno M, Militerni R, Di Maio S, Bravaccio C, Gasparini N, Tenore A 1999 Intellectual outcome at 12 years of age in congenital hypothyroidism. Eur J Endocrinol 14:105-110.

175. Bess FH, Dodd-Murphy J, Parker RA 1998 Children with minimal sensorineural hearing loss: prevalence, educational performance, and functional status. Ear Hear 19: 339-354.

176. François $M$, Bonfils $P$, Leger J, Czernichow $P$, Narcy $P$ 1994 Role of congenital hypothyroidism in hearing loss in children. J Pediatr 124:444-446.

177. Rovet J, Walker W, Bliss B, Buchanan L, Ehrlich R 1996 Long-term sequelae of hearing impairment in congenital hypothyroidism. J Pediatr 128:776-783.

178. Bruno R, Aversa T, Catena M, Valenzise M, Lombardo F, De Luca F, Wasniewska M 2015 Even in the era of congenital hypothyroidism screening mild and subclinical sensorineural hearing loss remains a relatively common complication of severe congenital hypothyroidism. Hear Res 327:43-47.

179. Agretti P, Bagattini B, De Marco G, Di Cosmo C, Dionigi G, Vitti P, Tonacchera M 2016 Papillary thyroid cancer in a patient with congenital goitrous hypothyroidism due to a novel deletion in NIS gene. Endocrine 54:256-258.

180. Zhu H, Peng YG, Ma SG, Liu H 2015 TPO gene mutations associated with thyroid carcinoma: case report and literature review. Cancer Biomark 15:909-913.

181. Niedziela M 2006 Pathogenesis, diagnosis and management of thyroid nodules in children. Endocr Relat Cancer 13:427-453.

182. Şıklar Z, Berberoğlu M, Yağmurlu A, Hacıhamdioğlu B, Savaş Erdeve S, Fitöz S, Kır M, Öçal G 2012 Synchronous occurrence of papillary carcinoma in the thyroid gland and thyroglossal duct in an adolescent with congenital hypothyroidism. J Clin Res Pediatr Endocrinol 4:30-33.

183. Salerno M, Micillo M, Di Maio S, Capalbo D, Ferri P, Lettiero T, Tenore A 2001 Longitudinal growth, sexual maturation and final height in patients with congenital hypothyroidism detected by neonatal screening. Eur $\mathrm{J}$ Endocrinol 145:377-383.

184. Delvecchio M, Salerno M, Acquafredda A, Zecchino C, Fico F, Manca F, Faienza MF, Cavallo L 2006 Factors predicting final height in early treated congenital hypothyroid patients. Clin Endocrinol (Oxf) 65:693-697.

185. Soliman AT, Azzam S, Elawwa A, Saleem W, Sabt A 2012 Linear growth and neurodevelopmental outcome of children with congenital hypothyroidism detected by neonatal screening: a controlled study. Indian J Endocrinol Metab 16:565-568.

186. Dalili S, Rezvani SM, Dalili H, Mohtasham Amiri Z, Mohammadi H, Abrisham Kesh S, Novin MH, Medghalchi A, Gholamnezhad H 2014 Congenital hypothyroidism: etiology and growth-development outcome. Acta Med Iran 52:752-756.

187. Uyttendaele M, Lambert S, Tenoutasse S, Boros E, Ziereisen F, Van Vliet G, Heinrichs C, Brachet C 2016 Congenital hypothyroidism: long-term experience with early and high levothyroxine dosage. Horm Res Paediatr 85: 188-197. 
188. Hassani Y, Larroque B, Dos Santos S, Ecosse E, Bouyer J, Léger J 2012 Fecundity in young adults treated early for congenital hypothyroidism is related to the initial severity of the disease: a longitudinal population-based cohort study. J Clin Endocrinol Metab 97:1897-1904.

189. Williams GR, Bassett JHD 2018 Thyroid diseases and bone health. J Endocrinol Invest 41:99-109.

190. Leger J, Ruiz JC, Guibourdenche J, Kindermans C, Garabedian M, Czernichow P 1997 Bone mineral density and metabolism in children with congenital hypothyroidism after prolonged L-thyroxine therapy. Acta Paediatr 86: 704-710.

191. Salerno M, Lettiero T, Esposito-del Puente A, Esposito V, Capalbo D, Crapinelli A, Padula S, del Puente A 2004 Effect of longterm L-thyroxine treatment on bone mineral density in young adults with congenital hypothyroidism. Eur J Endocrinol 151:689-694.

192. Kempers MJ, Vulsma T, Wiedijk BM, de Vijlder JJ, van Eck-Smit BL, Verberne HJ 2006 The effect of life-long thyroxine treatment and physical activity on bone mineral density in young adult women with congenital hypothyroidism. J Pediatr Endocrinol Metab 19:14051412.

193. Karakaş NM, Tulgar Kınık S, Özdemir B, Muratoğlu Şahin N, Tekindal MA, Haberal A 2017 Congenital hypothyroidism and bone remodeling cycle. J Clin Res Pediatr Endocrinol 9:106-110.

194. Wong SC, Ng SM, Didi M 2004 Children with congenital hypothyroidism are at risk of adult obesity due to early adiposity rebound. Clin Endocrinol (Oxf) 61:441446.

195. Livadas S, Magiakou MA, Mengreli C, Girginoudis P, Galani C, Smyrnaki P, Kanaka-Gantenbein C, Xekouki P, Chrousos GP, Dacou-Voutetakis C 2007 Obesity and attenuated adiposity rebound in children with congenital hypothyroidism. Normalization of BMI values in adolescents. Horm Metab Res 39:524-528.

196. Chen SY1, Lin SJ, Lin SH, Chou YY 2013 Early adiposity rebound and obesity in children with congenital hypothyroidism. Pediatr Neonatol 54:107-112.

197. Akin MA, Sarici D, Yikilmaz A, Akin L, Gunes T, Ozturk MA, Kurtoglu S 2013 Aortic intima-media thickness in newborns with congenital hypothyroidism. Horm Res Paediatr 80:267-272.

198. Öner T, Özdemir R, Doksöz Ö, Yozgat Y, Karadeniz C, Demirpençe S, Yılmazer MM, Büyükinan M, Meşe T, Tavlı V 2015 Cardiac function in newborns with congenital hypothyroidism: association with thyroidstimulating hormone levels. J Clin Res Pediatr Endocrinol 7:307-311.

199. Arslan A, Baş VN, Uytun S, Poyrazoğlu HG 2017 Effects of L-thyroxine treatment on heart functions in infants with congenital hypothyroidism. J Pediatr Endocrinol Metab 30:557-560.

200. Salerno M, Oliviero U, Lettiero T, Guardasole V, Mattiacci DM, Saldamarco L, Capalbo D, Lucariello A, Saccà L, Cittadini A 2008 Long-term cardiovascular effects of levothyroxine therapy in young adults with congenital hypothyroidism. J Clin Endocrinol Metab 93: 2486-2491.

201. Oliviero U, Cittadini A, Bosso G, Cerbone M, Valvano A, Capalbo D, Apuzzi V, Clabrese F, Lettiero T, Salerno M 2010 Effects of long-term L-thyroxine treatment on endothelial function and arterial distensibility in young adults with congenital hypothyroidism. Eur J Endocrinol 162:289-294.

202. Bisacchi N, Bal MO, Nardi L, Bettocchi I, d'Addabbo G, Conti V, Monti S, D’Alberton F, Cicognanni A, Cassio A 2011 Psychological and behavioural aspects in children and adolescents with congenital hypothyroidism diagnosed by neonatal screening: comparison between parents' and children's perceptions. Eur J Endocrinol 164:269-276.

203. van der Sluijs Veer L, Kempers MJE, Stam HM, Last BF, Vulsma T, Grootenhuis MA 2012 Health-related quality of life and self-worth in 10-year old children with congenital hypothyroidism diagnosed by neonatal screening. Child Adolesc Psychiatry Ment Health 6:32.

204. van der Sluijs Veer L, Kempers MJ, Last BF, Vulsma T, Grootenhuis MA 2008 Quality of life, developmental milestones, and self-esteem of young adults with congenital hypothyroidism diagnosed by neonatal screening. J Clin Endocrinol Metab 93:2654-2661.

205. Sato H, Nakamura N, Harada S, Kakee N, Sasaki N 2009 Quality of life of young adults with congenital hypothyroidism. Pediatr Int 51:126-131.

206. Rachas A, Lefeuvre D, Meyer L, Faye A, Mahlaoui N, de La Rochebrochard E, Warszawski J, Durieux P 2016 Evaluating continuity during transfer to adult care: a systematic review. Pediatrics 138:e20160256.

207. Rachas A, Tuppin P, Meyer L, Falissard B, Faye A, Mahlaoui N, de La Rochebrochard E, Frank M, Durieux P, Warszawski J 2018 Excess mortality and hospitalizations in transitional-age youths with a long-term disease: a national population-based cohort study. PLoS One 13: e0193729.

208. Carré A, Szinnai G, Castanet M, Sura-Trueba S, Tron E, Broutin-L'Hermite I, Barat P, Goizet C, Lacombe D, Moutard ML, Raybaud C, Raynaud-Ravni C, Romana S, Ythier H, Léger J, Polak M 2009 Five new TTF1/NKX2.1 mutations in brain-lung-thyroid syndrome: rescue by PAX8 synergism in one case. Hum Mol Genet 18:22662276.

209. Deladoey J, Ruel J, Giguere Y, Van Vliet G 2011 Is the incidence of congenital hypothyroidism really increasing? A 20-year retrospective population-based study in Quebec. J Clin Endocrinol Metab 96:2422-2429.

210. Szinnai G 2014 Clinical genetics of congenital hypothyroidism. Endocr Dev 26:60-78.

211. Abu-Khudir R, Larrivee-Vanier S, Wasserman JD, Deladoey J 2017 Disorders of thyroid morphogenesis. Best Pract Res Clin Endocrinol Metab 31:143-159.

212. Schoenmakers N, Chatterjee VK 2015 Thyroid gland: TSHR mutations and subclinical congenital hypothyroidism. Nat Rev Endocrinol 11:258-259.

213. Stoupa A, Kariyawasam D, Carré A, Polak M 2016 Update of thyroid developmental genes. Endocrinol Metab Clin North Am 45:243-254.

214. Fernandez LP, Lopez-Marquez A, Santisteban P 2015 Thyroid transcription factors in development, differentiation and disease. Nat Rev Endocrinol 11:29-42.

215. Marelli F, Persani L 2018 Role of Jagged1-Notch pathway in thyroid development. J Endocrinol Invest 41: 75-81.

216. Carré A, Stoupa A, Kariyawasam D, Gueriouz M, Ramond C, Monus T, Leger J, Gaujoux S, Sebag F, Glaser N, Zenaty D, Nitschke P, Bole-Feysot C, Hubert L, Lyonnet S, Scharfmann R, Munnich A, Besmond C, Taylor W, 
Polak M 2017 Mutations in BOREALIN cause thyroid dysgenesis. Hum Mol Genet 26:599-610.

217. Opitz R, Hitz MP, Vandernoot I, Trubiroha A, AbuKhudir R, Samuels M, Desilets V, Costagliola S, Andelfinger G, Deladoey J 2015 Functional zebrafish studies based on human genotyping point to netrin-1 as a link between aberrant cardiovascular development and thyroid dysgenesis. Endocrinology 156:377-388.

218. Stoupa A, Adam F, Kariyawasam D, Strassel C, Gawade S, Szinnai G, Kauskot A, Lasne D, Janke C, Natarajan K, Schmitt A, Bole-Feysot C, Nitschke P, Leger J, JabotHanin F, Tores F, Michel A, Munnich A, Besmond C, Scharfmann R, Lanza F, Borgel D, Polak M, Carré A 2018 TUBB1 mutations cause thyroid dysgenesis associated with abnormal platelet physiology. EMBO Mol Med 10: e9569.

219. Thorwarth A, Schnittert-Hubener S, Schrumpf P, Muller I, Jyrch S, Dame C, Biebermann H, Kleinau G, Katchanov J, Schuelke M, Ebert G, Steininger A, Bonnemann C, Brockmann K, Christen HJ, Crock P, deZegher F, Griese M, Hewitt J, Ivarsson S, Hubner C, Kapelari K, Plecko B, Rating D, Stoeva I, Ropers HH, Gruters A, Ullmann R, Krude H 2014 Comprehensive genotyping and clinical characterisation reveal 27 novel NKX2-1 mutations and expand the phenotypic spectrum. J Med Genet 51:375387.

220. Zou M, Alzahrani AS, Al-Odaib A, Alqahtani MA, Babiker O, Al-Rijjal RA, BinEssa HA, Kattan WE, Al-Enezi AF, Al Qarni A, Al-Faham MSA, Baitei EY, Alsagheir A, Meyer BF, Shi Y 2018 Molecular analysis of congenital hypothyroidism in Saudi Arabia: SLC26A7 mutation is a novel defect in thyroid dyshormonogenesis. J Clin Endocrinol Metab 103:1889-1898.

221. Cangul H, Liao XH, Schoenmakers E, Kero J, Barone S, Srichomkwun P, Iwayama H, Serra EG, Saglam H, Eren E, Tarim O, Nicholas AK, Zvetkova I, Anderson CA, Frankl FEK, Boelaert K, Ojaniemi M, Jääskeläinen J, Patyra K, Löf C, Williams ED; UK10K Consortium, Soleimani M, Barrett T, Maher ER, Chatterjee VK, Refetoff S, Schoenmakers N 2018 Homozygous loss-of-function muttaions in SLC26A7 cause goitrous congenital hypothyroidism. JCI Insight 3:e99631.

222. Kuhnen P, Turan S, Frohler S, Guran T, Abali S, Biebermann H, Bereket A, Gruters A, Chen W, Krude H 2014 Identification of PENDRIN (SLC26A4) mutations in patients with congenital hypothyroidism and "apparent" thyroid dysgenesis. J Clin Endocrinol Metab 99:E169E176.

222a. Stoupa A, Chaabane R, Guériouz M, Raynaud-Ravni C, Nitschke P, Bole-Feysot C, Mnif M, Ammar Keskes L, Hachicha M, Belguith N, Polak M, Carré A 2018 Thyroid hypoplasia in congenital hypothyroidism associated with thyroid peroxidase mutations. Thyroid 28: 941-944.

223. Srichomkwun P, Takamatsu J, Nickerson DA, Bamshad MJ, Chong JX, Refetoff S 2017 DUOX2 Gene mutation manifesting as resistance to thyrotropin phenotype. Thyroid 27:129-131.

224. Kizys MML, Louzada RA, Mitne-Neto M, Jara JR, Furuzawa GK, de Carvalho DP, Dias-da-Silva MR, NesiFranca S, Dupuy C, Maciel RMB 2017 DUOX2 mutations are associated with congenital hypothyroidism with ectopic thyroid gland. J Clin Endocrinol Metab 102:4060 4071.
225. Aycan Z, Cangul H, Muzza M, Bas VN, Fugazzola L, Chatterjee VK, Persani L, Schoenmakers N 2017 Digenic DUOX1 and DUOX2 mutations in cases with congenital hypothyroidism. J Clin Endocrinol Metab 102:30853090.

226. Parlato M, Charbit-Henrion F, Hayes P, Tiberti A, Aloi M, Cucchiara S, Begue B, Bras M, Pouliet A, Rakotobe S, Ruemmele F, Knaus UG, Cerf-Bensussan N 2017 First identification of biallelic inherited DUOX2 inactivating mutations as a cause of very early onset inflammatory bowel disease. Gastroenterology 153: 609.e3-611.e3.

227. Muzza M, Rabbiosi S, Vigone MC, Zamproni I, Cirello V, Maffini MA, Maruca K, Schoenmakers N, Beccaria L, Gallo F, Park SM, Beck-Peccoz P, Persani L, Weber G, Fugazzola L 2014 The clinical and molecular characterization of patients with dyshormonogenic congenital hypothyroidism reveals specific diagnostic clues for DUOX2 defects. J Clin Endocrinol Metab 99:544-553.

228. Lof C, Patyra K, Kuulasmaa T, Vangipurapu J, Undeutsch H, Jaeschke H, Pajunen T, Kero A, Krude H, Biebermann H, Kleinau G, Kuhnen P, Rantakari K, Miettinen P, Kirjavainen T, Pursiheimo JP, Mustila T, Jaaskelainen J, Ojaniemi M, Toppari J, Ignatius J, Laakso M, Kero J 2016 Detection of novel gene variants associated with congenital hypothyroidism in a finnish patient cohort. Thyroid 26:1215-1224.

229. Nicholas AK, Serra EG, Cangul H, Alyaarubi S, Ullah I, Schoenmakers E, Deeb A, Habeb AM, Almaghamsi M, Peters C, Nathwani N, Aycan Z, Saglam H, Bober E, Dattani M, Shenoy S, Murray PG, Babiker A, Willemsen R, Thankamony A, Lyons G, Irwin R, Padidela R, Tharian K, Davies JH, Puthi V, Park SM, Massoud AF, Gregory JW, Albanese A, Pease-Gevers E, Martin H, Brugger K, Maher ER, Chatterjee VK, Anderson CA, Schoenmakers N 2016 Comprehensive screening of eight known causative genes in congenital hypothyroidism with gland-insitu. J Clin Endocrinol Metab 101:4521-4531.

230. Miyai K, Azukizawa M, Kumahara Y 1971 Familial isolated thyrotropin deficiency with cretinism. N Engl J Med 285:1043-1048.

231. Bonomi M, Proverbio MC, Weber G, Chiumello G, BeckPeccoz P, Persani L 2001 Hyperplastic pituitary gland, high serum glycoprotein hormone alpha-subunit and variable circulating thyrotropin (TSH) levels as hallmark of central hypothyroidism duet o mutations of the TSH beta gene. J Clin Endocrinol Metab 86:1600-1604.

232. Ramos HE, Labedan I, Carré A, Castanet M, Guemas I, Tron E, Madhi F, Delacourt C, Maciel RM, Polak M 2010 New cases of isolatedcongenital central hypothyroidism due to homozygous thyrotropin beta gene mutations: a pitfall to neonatal screening. Thyroid 20:639-645.

233. Bonomi M, Busnelli M, Beck-Peccoz P, Costanzo D, Antonica F, Dolci C, Pilotta A, Buzi F, Persani L 2009 A family with complete resistance to thyrotropin-releasing hormone. N Engl J Med 360:731-734.

234. Sun Y, Bak B, Schoenmakers N, van Trotsenburg AS, Oostdijk W, Voshol P, Cambridge E, White JK, le Tissier P, Gharavy SN, Martinez-Barbera JP, StokvisBrantsma WH, Vulsma T, Kempers MJ, Persani L, Campi I, Bonomi M, Beck-Peccoz P, Zhu H, Davis TM, Hokken-Koelega AC, Del Blanco DG, Rangasami JJ, Ruivenkamp CA, Laros JF, Kriek M, Kant SG, Bosch CA, Biermasz NR, Appelman-Dijkstra NM, Corssmit 
EP, Hovens GC, Pereira AM, den Dunnen JT, Wade MG, Breuning MH, Hennekam RC, Chatterjee K, Dattani MT, Wit JM, Bernard DJ 2012 Loss-of-function mutations in IGSF1 cause an X-linked syndrome of central hypothyroidism and testicular enlargement. Nat Genet 44:1375-1381.

235. Joustra SD, Heinen CA, Schoenmakers N, Bonomi M, Ballieux BE, Turgeon MO, Bernard DJ, Fliers E, van Trotsenburg AS, Losekoot M, Persani L, Wit JM, Biermasz NR, Pereira AM, Oostdijk W: IGSF1 Clinical Care Group 2016 IGSF1 deficiency: lessons from an extensive case series and recommendations for clinical management. J Clin Endocrinol Metab 101:1627-1636.

236. Heinen CA, Losekoot M, Sun Y, Watson PJ, Fairall L, Joustra SD, Zwaveling-Soonawala N, Oostdijk W, van den Akker EL, Alders M, Santen GW, van Rijn RR, Dreschler WA, Surovtseva OV, Biermasz NR, Hennekam RC, Wit JM, Schwabe JW, Boelen A, Fliers E, van Trotsenburg AS 2016 Mutations in TBL1X are associated with central hypothyroidism. J Clin Endocrinol Metab 101:4564-4573.
237. Heinen CA, de Vries EM, Alders $M$, Bikker $H$, Zwaveling-Soonawala N, van den Akker ELT, Bakker B, Hoorweg-Nijman G, Roelfsema F, Hennekam RC, Boelen A, van Trotsenburg ASP, Fliers E 2018 Mutations in IRS4 are associated with central hypothyroidism. J Med Genet 55:693-700.

238. Ranzini AC, Ananth CV, Smulian JC, Kung M, Limbachia A, Vintzileos AM 2001 Ultrasonography of the fetal thyroid: nomograms based on biparietal diameter and gestational age. J Ultrasound Med 20:613-617.

Address correspondence to: Michel Polak, MD, PhD

Pediatric Endocrinology Gynecology and Diabetology Department

Hôpital Universitaire Necker Enfants Malades 149 Rue de Sèvres

Paris 75015

France

E-mail: michel.polak@aphp.fr 